Portland State University

PDXScholar

Spring 6-16-2015

\title{
The Multilevel Effects of Supervisor Adaptability on Training Effectiveness and Employee Job Satisfaction
}

Joseph Alvin Sherwood Portland State University

Follow this and additional works at: https://pdxscholar.library.pdx.edu/open_access_etds

Part of the Industrial and Organizational Psychology Commons, and the Work, Economy and Organizations Commons Let us know how access to this document benefits you.

\section{Recommended Citation}

Sherwood, Joseph Alvin, "The Multilevel Effects of Supervisor Adaptability on Training Effectiveness and Employee Job Satisfaction" (2015). Dissertations and Theses. Paper 2322.

https://doi.org/10.15760/etd.2319

This Thesis is brought to you for free and open access. It has been accepted for inclusion in Dissertations and Theses by an authorized administrator of PDXScholar. For more information, please contact pdxscholar@pdx.edu. 
The Multilevel Effects of Supervisor Adaptability on Training Effectiveness and Employee Job Satisfaction

$$
\text { by }
$$

Joseph Alvin Sherwood

A thesis submitted in partial fulfillment of the requirements for the degree of

\author{
Master of Science \\ in \\ Psychology
}

Thesis Committee:

Leslie Hammer, Chair

Donald Truxillo

Todd Bodner

Portland State University

2015 
Abstract

The present study explored the multilevel effects of supervisor learning adaptability on training effectiveness, and post-training employee job satisfaction in a work-family and safety-based intervention aimed at increasing family supportive supervisor behaviors (FSSB) and safety behaviors. Using a sample of 291 municipal public works field workers from two independent organizations, it was hypothesized that supervisor adaptability positively relates to post-training FSSB and employee job satisfaction. Specifically, it was hypothesized that learning adaptability prepares those supervisors to be more inclined to engage actively in training, thereby increasing employee reported FSSBs more significantly for those supervisors and leading to intervention target results, namely employee job satisfaction. Results did not support the hypothesized relationships. However, bivariate correlations between learning adaptability and FSSBs and job satisfaction are significant and positive, indicating that with a larger sample, learning adaptability may moderate training effectiveness. Theoretical rationale, methods, and scientific contributions are discussed. 
Table of Contents

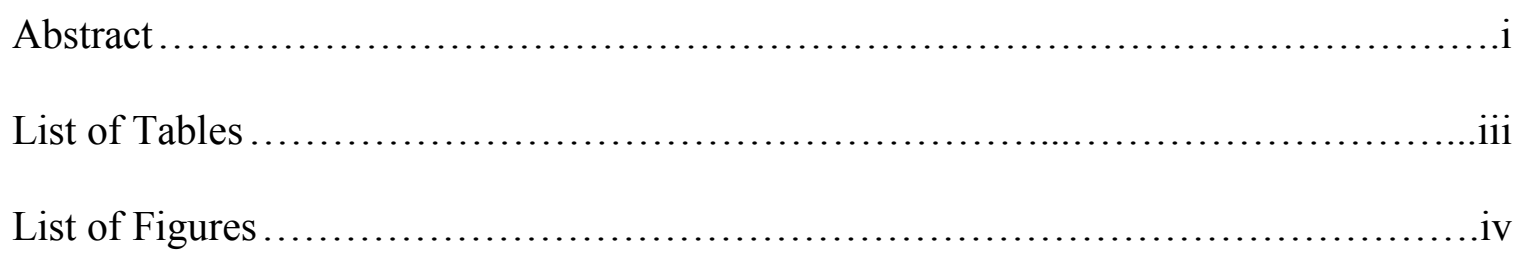

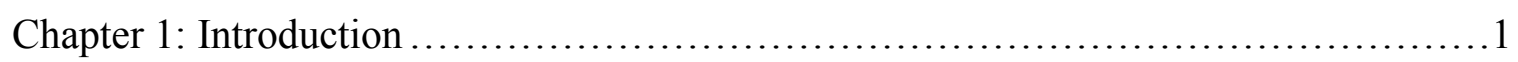

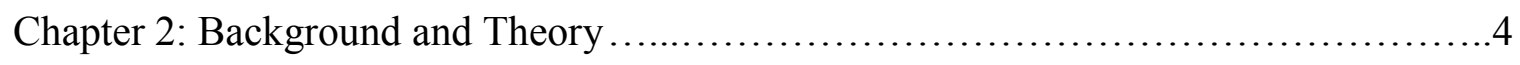

Chapter 3: Hypotheses .................................................... 27

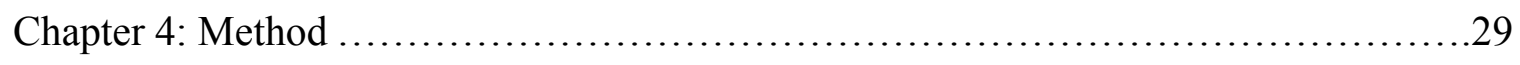

Chapter 5: Results ..................................................... 37

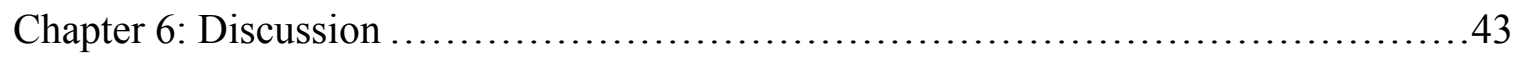

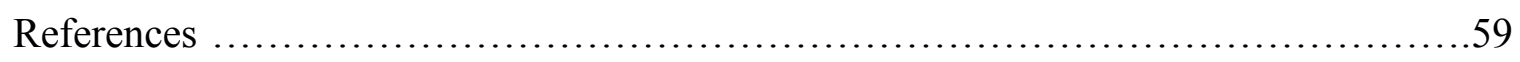

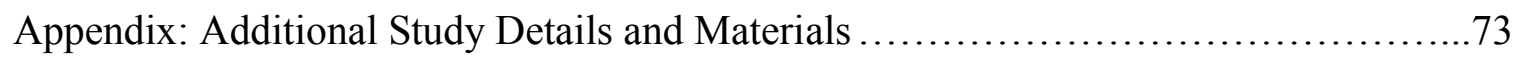




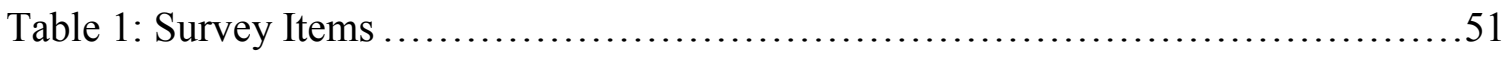

Table 2: Sample Characteristics............................................52

Table 3: Bivariate Correlations for Employee $(n=291)$ and Supervisor $(n=23)$

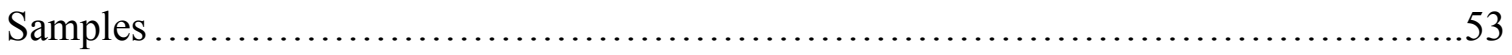

Table 4: Exploratory Factor Analysis (EFA) Results ..............................54

Table 5: Intercepts Only Models for Study Outcome Variables......................54

Table 6: Multilevel Model Results for Hypothesis One, the Effect of the Training on Six

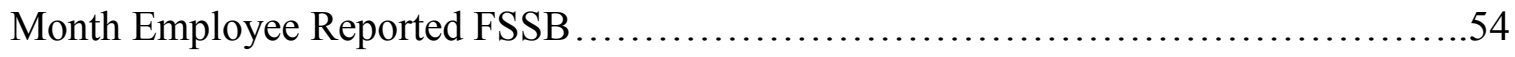

Table 7: Multilevel Model Results from Hypothesis Two, the Effect of Supervisor

Learning Adaptability by Treatment on Six Month Employee Reported FSSB ..........55

Table 8: Multilevel Model Results From Hypothesis Three, the Effect of the Training on

Six Month Employee Job Satisfaction ..........................................55

Table 9: Multilevel Model Results From Hypothesis Four, the Effect of Supervisor

Learning Adaptability by Treatment on Six Month Employee Job Satisfaction ...........56

Table 10: Means and Standard Deviations for Employee and Supervisor Samples on

Primary Study Variables ...................................................... 56 
List of Figures

Figure 1: Theoretical Model of Hypotheses and Predicted Relationships ................57

Figure 2: Estimate of Statistical Power for Treatment and Control Groups ...............58 


\section{CHAPTER 1}

\section{Introduction}

Constant and dramatic environmental changes have prompted the need for costly training programs within organizations (Cascio, 2003). Economic recessions, technological advances, shifts in the type of work people to, globalization, and an increasingly diverse workforce all contribute to increases in inter- and intraorganizational competition and threaten organizational success if leaders and employees fail to learn and adapt to the ever shifting environmental contexts. Further, the compounded influence of these environmental shifts often result in demands that decrease employee health and well-being, which is becoming an increasing concern for organizations and researchers (Quick \& Tetrick, 2011). To face these challenges, organizations spend an estimated $\$ 135$ billion annually on training individuals in the United States alone (Patel, 2010). Given the costly nature of training, research examining factors that influence training effectiveness is vitally important.

Dispositional and motivational characteristics have been shown to enhance training proficiency (Barrick \& Mount, 1991; Burke \& Hutchins, 2007). Some personality characteristics receiving consistent support are openness to experience, extraversion, and proactive personality (Barrick \& Mount, 1991; Burke \& Hutchins, 2007; Fuller \& Marler, 2009). Major, Turner, and Fletcher (2006) demonstrated that openness to experience, extraversion, and proactive personality were linked to motivation to learn, which predicted development activity.

Another potential dispositional characteristic that may be related to training effectiveness is adaptability. Fairly recently, the personality-like construct of adaptability 
was developed (Ployhart \& Bliese, 2006). Previous research has mostly examined adaptability as a measure of task performance (Pulakos, Arad, Donovan, \& Plamandon, 2000). Ployhart and Bliese (2006) expounded on the work by Pulakos et al. (2000), creating a trait-based measure of adaptability. Ployhart and Bliese (2006) define adaptability as a person's ability, willingness, and motivation to change or conform to task, social, or environmental elements and includes the eight sub-dimensions of: 1) crisis adaptability, 2) work stress adaptability, 3) creative adaptability, 4) uncertainty adaptability, 5) cultural adaptability, 6) physical adaptability, 7) learning adaptability, and 8) interpersonal adaptability. Because this research focuses on training effectiveness and learning is a major component of training, I have chosen to use a single subdimension of adaptability, learning adaptability, which refers to a person's tendency, ability, and openness to learn and apply new skills. The effects of this personality trait have yet to be explored in the training effectiveness literature, and more specifically in the area of supervisor training effectiveness.

As will be shown, learning adaptability may be especially relevant for training effectiveness because it is operationally similar to other personality traits that have been shown to be related to training effectiveness like openness to experience and proactive personality. Hammer, Kossek, Anger, Bodner and Zimmerman (2011) conducted one of the few work-family intervention studies to date. They found that Family Supportive Supervisor Behaviors (FSSBs) led to improved reports of job satisfaction, perceived health, and intentions to turnover among their employees. This training highlights the importance of flexibility, expressing empathy and emotional support for family-related concerns, role modeling effective work-family integration strategies, and creative work- 
family management. Despite the reported findings of FSSB training success, no research has explored supervisor level characteristics associated with such effectiveness. Furthermore, the role of supervisor personality, and more specifically, learning adaptability, on FSSB training effectiveness, training effectiveness more generally, and its ultimate impact on employee job satisfaction have not been examined. Thus, the present study examines the role of supervisor trait-based learning adaptability on training effectiveness, and the subsequent multi-level effects on employee job satisfaction (see Figure 1). 


\section{CHAPTER 2}

\section{Background and Theory}

\section{Adaptability}

Task performance adaptability. Adaptability as a personality trait is a fairly recent development (Ployhart \& Bliese, 2006). Thus, research that applies adaptability as a dispositional trait is very limited. Traditionally, researchers have examined adaptability as a form of task performance. Research has measured the degree of adaptive performance by the successful fulfillment of changing tasks (Allworth \& Hesketh, 1999; LePine, Colquitt, \& Erez, 2000). For example, LePine and colleagues (2000) assessed adaptive performance by measuring the degree to which participants were able to aptly solve problems when the rules for selecting a correct response unknowingly changed midway through. Participants with higher levels of cognitive ability and openness to experience, and lower levels of conscientiousness, demonstrated a higher success rate for confronting the dynamic tasks. Research has also explored adaptive performance within transitional job stages. In one study, a sample undergoing a transition was compared to another sample maintaining the status quo (Thoresen, Bradley, Thoresen, \& Bliese, 2004). They found that openness to experience and agreeableness predicted sales performance within a transitional sample, but not the maintenance sample. These studies demonstrate the importance that individual differences play in adaptive performance. Regardless, the conceptualization of adaptability as an individual difference variable, rather than an outcome dependent on individual difference variables, has received very little attention, specifically with regard to training effectiveness.

Adaptability and training. The training transfer literature has indirectly treated 
the topic of adaptability in that transfer refers to an individual's ability to maintain learned knowledge and behaviors gained from a training exercise and both apply and generalize them to job tasks (Baldwin \& Ford, 1988). Thus, adaptive performance in this vein would reflect how well individuals accomplish this act. A program of research by Kozlowski and colleagues (Bell \& Kozlowski, 2008; Kozlowski, 1998; Kozlowski, Gully et al., 2001; Kozlowski, Toney et al., 2001) has quantified performance adaptability by predicting generalization to more difficult and complex versions of a task learned in training. One study examined the performance adaptability of 60 individuals after taking part in a complex, two-day, computer simulation training. Results showed that selfefficacy and knowledge structure coherence predicted adaptive performance. Specifically that higher self-efficacy and knowledge structure coherence (determined by how well participants made interconnections between various concepts) predicted successful generalization to new, more complex tasks when they were introduced during training (Kozlowski, Toney et al., 2001). The link between self-efficacy and adaptive performance has been shown to be mediated by motivational and regulation processes (Chen, Thomas, \& Wallace, 2005). In this study, the link between self- and team-efficacy and adaptive performance of a training exercise was fully mediated by goal choice and striving.

Although this body of research demonstrates that adaptive performance is mediated by individual-level characteristics (e.g., cognitive ability, personality, motivation), and functions to predict successful transfer, a cohesive taxonomy of performance adaptability did not emerge until Pulakos et al. (2000) proposed a model that included eight sub-dimensions of adaptive performance. These were 1) handling 
emergencies or crisis situations, 2) handling work stress, 3) solving problems creatively, 4) dealing with uncertain and unpredictable work situations, 5) learning work tasks, technologies, and procedures, 6) demonstrating interpersonal adaptability, 7) demonstrating cultural adaptability, and 8) demonstrating physically oriented adaptability. In order to arrive at the eight sub-dimensions, Pulakos and colleagues reviewed past literature, as well as analyzed 1000 critical incidents from 21 jobs. Results from the content analysis confirmed the validity of this taxonomy. Thus, this research demonstrated that a) performance adaptability is multi-dimensional, and b) that the relevance of a given individual sub-dimension of adaptability depends on the job. For example, for a computer programmer, physically oriented adaptability will likely not dictate successful job performance.

Individual adaptability (I-ADAPT) theory. One issue inherent in the majority of research investigating adaptability is that the criterion is defined by changing tasks, which confines the measurement of adaptability to task-specific terms. Further, the few individual difference variables used to predict task performance related adaptability are wholly dependent on the context and criterion they are intended to predict, which creates problems for a theory that generalizes across varying jobs, tasks, and situations. Further, by focusing on adaptability as a performance measure, researchers limit the ability to identify determinants and consequences of individual adaptability.

To remedy these apparent issues with the measurement of adaptability, Ployhart and Bliese (2006) proposed the Individual Adaptability (I-ADAPT) Theory, and created a multi-dimensional measure based on work by Pulakos et al. (2000) to evaluate the latent construct within individuals. I-ADAPT theory diverges from previous conceptions of 
adaptability by moving into a framework more centered on the person, and less on the environment. Specifically, they define adaptability as "an individual's ability, skills, disposition, willingness, and/or motivation, to change or fit different task, social, and environmental features." (p. 13). This definition creates some distinctions from previous definitions of adaptability.

First, within this framework, the focus of adaptability is centered within the individual. Adaptability, therefore, reflects individual differences and can be viewed as a stable trait, regardless of changes that may occur in the environment. Second, this approach differs from previous definitions of adaptability in that it is not a task performance, but rather a composite of various knowledge, skills, abilities, and other characteristics (KSAOs). The distinction is that the focus of I-ADAPT to the individual, as opposed to differences in performance, creates an operationalization independent of the performance context. In other words individual adaptability will operate in any context in which it is required. Third, the definition emphasizes a proactive and reactive component. In the case of proactivity, individual appraises a stable situation as needing change. In contrast, a reactive response occurs when a dynamic environment requires changes within the individual to fit within this context (Ployhart \& Bliese, 2006).

The I-ADAPT Measure (I-ADAPT-M) assesses eight sub-dimensions of individual adaptability, 1) crisis adaptability, which refers to an individual's capacity to resolve crisis situations when they arise, 2) work stress adaptability, which refers to an individual's ability to react and cope positively with stressful stimuli, 3) creative adaptability, which refers to an individual's ability and tendency to come up with creative solutions to unique problems, 4) uncertainty adaptability, which is defined as an 
individual's ability to positively manage uncertain situations, 5) cultural adaptability, which refers to an individual's level of cultural sensitivity and ability to interact in positive ways with diverse cultural elements, 6) physical adaptability, which is defined as a person's ability to meet new or changing physical demands effectively, 7) learning adaptability, which refers to a person's tendency, ability, and openness to learn and apply new skills, and 8) interpersonal adaptability, which refers to a person's propensity and capacity to interact in positive ways with others.

Despite the apparent value of such a construct, little research has come forth to explore its utility and validity except two published studies to have used the measure. One study, using a Chinese sample, examined the relationship between newcomer dimensions of adaptability (cultural adaptability, work stress adaptability, interpersonal adaptability, and learning adaptability) and work related outcomes, as well as the meditational role of person-environment (P-E) fit variables in this relationship (Wang, Zhan, McCune, \& Truxillo, 2011). This study found that adaptability dimensions were differentially associated with newcomers' perceptions of P-E fit variables over time and that P-E fit perceptions predicted levels of job performance, job satisfaction, and turnover intentions. These findings suggest that employee job satisfaction, job performance, and longevity are partially and differentially dependent on individual adaptability during uncertain times and environments that require learning. However, while it can be assumed that some level of training occurs when employees shift organizations, this study did not focus on the role of individual adaptability in the effectiveness of training experiences. 
A second study sought to remedy the problem of the un-validated individual adaptability measure (Hamtiaux, Houssemand, \& Vrignaud 2013). The focus of the paper was two-fold, 1) to confirm the factor structure of the construct and sub-dimensions, and 2) test the convergent validity. The confirmatory factor analysis (CFA) revealed that all eight sub-dimensions, but physical adaptability fit the unidimensionality of the hypothesized model. Results from a second CFA confirmed a second-order factor structure of the eight unique sub-dimensions, but only moderately so.

In order to test the construct validity (specifically, convergent validity) of the measure, the authors included both the I-ADAPT measure, as well as the Career AdaptAbilities Scale (CAAS), which they believed would correlate with the I-ADAPT measure. The CAAS measures four constructs, concern, control, curiosity, and confidence. The authors hypothesized that the crisis dimension would relate to control and confidence, creativity, cultural, interpersonal, and learning adaptability would relate to curiosity, physical adaptability would relate to confidence, and work stress and uncertainty to relate to confidence and control.

Results from the analysis revealed that composite scores from both scales correlated moderately $(r=.60)$. Furthermore, crisis correlated moderately with both control $(r=.42)$ and the confidence $(r=.38)$ dimensions. Creativity correlated with curiosity $(r=.45)$, cultural and interpersonal were also moderately correlated with curiosity as hypothesized $(r=.39)$ and $(r=.38)$, respectively. The learning dimension correlated with both curiosity $(r=.51)$ and confidence $(r=.53)$ as expected. The physical dimension correlated significantly but weakly with confidence $(r=.25)$. Additionally, work stress was correlated moderately with control $(r=.35)$ and confidence $(r=.32)$. 
And finally, the uncertainty dimension moderately correlated with both the control ( $r=$ $.52)$ and $(r=.51)$ dimensions as hypothesized. These results help to validate the convergent validity of individual adaptability with related constructs within the nomological network. As the overall dimension and the sub-dimensions relate only moderately, it can also be assumed that the measure has a level of discriminate validity (at least with the CAAS).

This measure is still in its infancy, and there remain a number of validation techniques that should be used to further test the measure. Specifically, as this measure has only been validated with a single sample, external validity and generalizability cannot be inferred before more studies use the measure with diverse samples. Furthermore, the measure lacks criterion validity. The Hamtiaux et al. (2013) study failed to test the measure's predictive or concurrent validity by running hierarchical regression analyses with a hypothesized criterion. It could be argued that by running a CFA, the authors tested the content and structural validity of the measure. However, it would be difficult to say whether or not the measure lacks a component of adaptability that should be included. Although the items within the I-ADAPT measure seem to have face validity, and its convergent validity has been confirmed, the measure is still in its infancy and further studies are needed to confirm these results as well as obtain external, content, structural, and criterion related validities. The present study seeks to expound on the validation work of Hamtiaux et al. (2013) by using the construct to predict supervisor training effectiveness, thereby exploring criterion validity.

\section{Training Effectiveness}

Training effectiveness is a broad term that has been used in the literature to 
describe a variety of training related outcomes, such as learning, transfer, or the measure of positive outcomes that are theorized to be a result of training (e.g., decreased turnover intentions, increased health, or job satisfaction, etc.). It may also refer to the measurement of training evaluation criteria frameworks. For example, training effectiveness might be assessed using Kirkpatrick's (1998) four-level approach, which evaluates the effectiveness of a training program by an assessment of trainee reactions (how much trainees like the training), learning (degree of skills or knowledge learned), behavior (on the job behavior change), and results (the outcome of training; e.g., return on investment or fewer accidents/errors). Critics have pointed out that these evaluation criteria are lacking in description and fail to fully grasp outcomes associated with a training program (Holton, 1996; Kauffman \& Keller, 1994; Phillips \& Phillips, 2002). Due to the vagueness of the Kirkpatrick model, more contemporary frameworks have been constructed that either elaborate on the meaning of each of the four levels (Alliger, Tannenbaum, Bennett, Traver, \& Shotland, 1997) or focus primarily on variations of learning outcomes (Kraiger, Ford, \& Salas, 1993). In the review of the training literature to follow, training effectiveness maintains this broad definition, referring to a variety of measures that describe how well a given training program leads to a desired outcome. However, this investigation uses the term training effectiveness to refer to post-training employee ratings of FSSB and employee self-reports of job satisfaction, while controlling for baseline levels of FSSB and job satisfaction. Given the behavioral, on the job, nature of the FSSB post-training outcome measure, training effectiveness in this instance might most closely be classified as training transfer, while post training job satisfaction could fit within the 'results' component of Alliger and colleague's (1997) training evaluation 
criteria. While a number of theories have been advanced to explain variables that influence training effectiveness, I primarily focus on the individual characteristics of motivation and personality, as they are most relevant to this investigation. Specifically, the following review serves to show that learning adaptability may relate to training effectiveness by acting as a personality trait that facilitates and motivates learning. It is important to note that although the focus of this study is the effect of individual level variables on training effectiveness, several broader level variables also influence training effectiveness. For example, organizational support for training (Noe \& Wilk, 1993), goal setting theory (Richman-Hirsch, 2001), opportunity to perform (Qui.ones, Ford, Sego, \& Smith, 1995), and guided reflection (Lee \& Sabatino, 1998) all have been shown to influence training effectiveness. Thus, given that the training program of interest in this study adheres to training practices that have been theoretically shown to increase training effectiveness, I seek to account for additional variance provided by supervisor learning adaptability. For a more comprehensive review of training theories, I refer the reader to Salas, Tannenbaum, Kraiger, and Smith-Jensch (2012).

Motivation to learn. While I did not specifically evaluate motivation to learn in this study, it is important to review the theoretical basis for how this construct relates to training effectiveness, as an understanding serves to explain relationships that I measure. In other words, by reviewing the literature on this construct, I demonstrate how the construct, motivation to learn, provides partial justification for the proposed relationship between adaptive personality and training effectiveness.

For an organization investing in a training program, it is prudent to understand the factors that influence trainee motivation. After all, as research has shown, a person's 
motivation affects the degree of zeal or apathy for learning new knowledge, skills, or abilities (KSAs), and this engagement or lack of engagement ultimately determines the success of the training (Colquitt, LePine, \& Noe, 2000). Several factors impact an individual's motivation to participate in training activities. A meta-analysis by Colquitt et al. (2000) revealed that varying levels of analysis (e.g., macro vs. micro) have been examined within the literature as explanatory mechanisms driving training motivation. In this analysis, a number of individual difference variables were shown to hold relationships with motivation to learn and several training effectiveness outcomes, including self-efficacy, having an internal locus of control, conscientiousness, and valence, to name a few. Path analyses revealed that motivation to learn completely mediated the relationship between more distal learning variables at all levels (i.e., individual, job, and organizational) and all four training effectiveness outcome variables (e.g., declarative knowledge, skill acquisition, post-training self-efficacy, and reactions), over and above cognitive ability (Colquitt et al., 2000).

Personality. Research has shown that personality impacts motivation to learn as well as training effectiveness outcomes. Most notably, Barrick and Mount (1991) metaanalyzed the relationship between Big Five personality dimensions and various jobperformance criteria. Among those relationships examined, three of the five dimensions, extraversion, openness to experience, and conscientiousness, exhibited relationships with training proficiency, with extraversion being chief among them $(\rho=.26)$, closely followed by openness to experience $(\rho=.25)$, and conscientiousness $(\rho=.23)$. Despite these findings, conscientiousness has proven to have a variable relationship with training effectiveness. (Let's divide this sentence into two and help the reader follow it more 
easily -as it is almost a 8-sentence paragraph) While some studies showed a positive relationship with training (Barrick \& Mount, 1991; Stewart, 1999), others showed a negative relationship (Stewart, Carson, \& Cardy, 1996), some demonstrated no relationship (Herold, Davis, Fedor, \& Parsons, 2002; Lee \& Klein, 2002), and finally a number of studies demonstrated that the predictive influence of conscientiousness depends on the skills being learned and/or the use of narrow facets, rather than broad factors of the trait (Dean, Conte, \& Blankenhorn, 2006; Dudley, Orvis, Lebiecki, \& Cortina, 2006; LePine et al., 2000).

Another meta-analysis specifically examining transfer of training, found that conscientiousness, self-efficacy, and motivation to learn were positively related to transfer (Blume, Ford, Baldwin, \& Huang, 2010). Similarly, Naquin and Holton (2002) found that certain dimensions of the Big Five and some state-like individual characteristics were positively related to motivation to improve work through learning. Specifically, they found that positive affect and extraversion were directly related to this outcome. Conscientiousness and agreeableness, on the other hand, were related to motivation to improve work through learning, but this relationship was mediated by a person's level of work commitment.

In contrast to these findings, Herold et al. (2002) did not find a relationship between conscientiousness and training effectiveness. Using a sample of potential pilots, participating in two phases of aviation training, openness, and emotional stability (neuroticism), were directly and negatively related to the time it took participants to successfully complete phase II training. In other words, those scoring high in these personality dimensions completed training tasks during phase II more quickly than their 
counterparts. Despite the fact that conscientiousness did not have direct effects, results revealed an interaction between conscientiousness, phase I learning, and phase II learning. Specifically, those with slow phase I learning times, but high conscientiousness, had much quicker learning times at phase II. It seems that conscientiousness aided participants who did poorly in phase I to improve significantly during phase II, perhaps due to characteristic resilience and goal setting behavior. Conversely, high phase I learning led to higher phase II learning for those high in emotional stability. It seems that this trait helped participants better capitalize on prior success.

In another study, for 97 participants undergoing a computer skills training course, self-deception and self-efficacy mediated the relationship between conscientiousness and learning. In this study, conscientiousness had a complex relationship with learning (Martocchio \& Judge, 1997). In other words, those with high conscientiousness were more likely to engage in self-deception, and self-deception was negatively related to learning. However, conscientiousness was related to self-efficacy, which had a positive relationship with learning. This study may explain some of the mixed findings surrounding conscientiousness and training related criteria.

Within an expectancy theory framework, Colquitt and Simmering (1998) examined the inter-relationships of goal orientation, conscientiousness, motivation to learn, and learning performance during a six-week management course, among a sample of 103 college students. Goal orientation is hypothesized to be a stable dispositional variable divided into two sub-dimensions: 1) learning orientation, and 2) performance orientation. Much like learning adaptability, as discussed previously, it is theorized that high learning orientation individuals are more likely to seek out challenges and learning 
opportunities, whereas those with performance orientation tend to avoid challenging tasks for more moderate or easy ones. Further, it is argued that individuals have predispositions that prompt them to respond differently to environmental cues, but that situational stimuli can influence those predispositions. (Button, Mathieu, \& Zajac, 1996). In this study, Colquitt and Simmering (1998) found that learning goal orientation related to motivation to learn and eventual performance through expectancy and valence. Specifically, results demonstrated that having a high learning orientation buffered learners against the negative effects of early learning challenges. Further, conscientiousness was demonstrated to positively predict both motivation to learn and performance. In the end, this investigation revealed that learners with the combination of high conscientiousness, a high learning goal orientation, and lower performance goal orientation, were $30 \%$ more likely to perform well on the first exam and $28 \%$ more likely to perform well on the second exam, suggesting that learning goal oriented individuals may be more dispositionally prepared to succeed in learning activities (i.e., training). To complement the findings of this study, Chen, Gully, Whiteman, and Kilcullen (2000) found that learning goal orientation, cognitive ability, and trait-based self-efficacy related to learning performance, and that this relationship was mediated by state self-efficacy and goal setting behavior.

Another personality characteristic receiving budding attention in the training effectiveness literature is proactive personality. Proactive personality is defined as the "[tendency to] identify opportunities and act on them, show initiative, take action, and persevere until meaningful change occurs," (Crant, 2000; p. 439) and has been shown to be empirically distinct from Big Five personality dimensions (Major et al., 2006). While 
the relationship between this personality trait and training effectiveness is still being studied, a meta-analysis has confirmed the positive predictive utility of proactive personality on various job performance criteria (Fuller \& Marler, 2009). One study demonstrated that proactive personality helps employees to cope with strain when job demands are high. Further, proactive personality increases perceptions of jobperformance when job control is high when compared to passive counterparts who seemed unaffected by job control, which may help to explain the relationship between proactive personality and job performance criteria (Parker \& Sprigg, 1999). Although the aforementioned meta-analysis did not examine the relationship between proactive personality and training effectiveness, Fuller and Marler (2002) urged scientists to examine this relationship in future research.

In a related vein, Major et al. (2006) examined the effects that conscientiousness, openness to experience, extraversion, and proactive personality had on motivation to learn and subsequent development activity. Development activity was assessed by the level to which participants took advantage of various training opportunities offered by their organization. Results showed that conscientiousness, openness to experience, and extraversion all related positively to motivation to learn. Moreover, proactive personality had incremental predictive utility over and above all Big Five personality dimensions with motivation to learn. Results showed that motivation to learn had a direct relationship with development activity. The relationship between proactive personality, extraversion, and openness to experience and development activity was mediated by motivation to learn.

The literature reviewed serves to demonstrate that personality characteristics have 
been consistently shown to relate to training effectiveness or related learning performance. With special relevance to this investigation, openness to experience, extraversion, learning goal orientation, and proactive personality have all shown to positively predict training effectiveness, learning, or training related criteria. This is of particular interest due to their similarity with learning adaptability in terms of their relation with training motivation. All of these personality traits appear to share common tenets. For example, openness to experience, learning orientation, proactive personality, and learning adaptability all share a unique component. Specifically, these individuals are predisposed, and motivated, to seek out such opportunities, take intrinsic enjoyment from, and succeed in, learning. Like proactive personality, a characteristic of learning adaptability is the tendency to initiate self-starting behavior that is useful in training contexts.

While I have just elaborated on similarities between proactive personality, openness to experience, and learning adaptability, their differences also justify the use of a measure of adaptability over any of the other personality constructs to predict training effectiveness. Specifically, proactive personality differs in that it is not specifically relevant to a training context in the way that learning adaptability is. This is because proactive personality speaks to a person's proactive nature more generally, whereas learning adaptability relates to proactive behavior with regards to learning activities specifically. Furthermore, proactive personality focuses on changing environmental characteristics as opposed to changing the self (Seibert, Crant, \& Kraimer, 1999; Wang et al., 2011). As FSSB training targets supervisors, and not necessarily organizational change, learning adaptability may have more predictive utility for training effectiveness 
over proactive personality. Further, openness to experience has been criticized for its broad definition, which has served as an explanation for weak predictive utility in other job performance criteria (Griffin \& Hesketh, 2004). Thus, it is likely that several components of openness to experience would simply serve to muddy training effectiveness predictive validity. Moreover, openness to experience does not necessarily imply activation of self-changing behaviors, and lacks context specificity for the target of trait related cognition and behavior (McCrae, 1996; Wang, et al., 2011). Thus, while proactive personality and openness to experience have been shown to predict training effectiveness, and share some similar tenets with learning adaptability, learning adaptability may be a more useful predictor in this context given its uniqueness as well as its similarity. For example, Wang et al. (2011) showed that cultural adaptability, work stress adaptability, interpersonal adaptability, and learning adaptability had incremental predictive utility over both proactive personality and openness to experience when predicting various newcomer person-environment fit variables. It has further been shown that specific, narrow traits, related to research outcome targets, are more useful predictors than more broad personality factors (Dudley et al., 2006; Hough \& Oswald, 2008). Despite these findings, no research to date has examined the relationship between traitbased learning adaptability (of supervisors or otherwise) and training effectiveness.

Psychosocial stress theories. To understand why family-specific supportive supervision is so important within organizations, it is important to summarize the literature that identifies relevant sources of workplace strain, and to discuss some theories seeking to explain the stressor-strain relationship. As mentioned previously, recent environmental developments have created sources of strain for employees. Among those 
relevant to this training are economic recessions, technological advances, globalization, more women entering the workforce, and an aging population (Hammer \& Zimmerman, 2011). As will be shown, certain aspects of all of these environmental changes have led to workplace stressors and employee strain by increasing work and family demands and amplifying role conflict. Further, these stress and role conflict theories are relevant to this study due to their relationship with employee job satisfaction.

Role Theory. Economic recessions, technological advances, globalization, more women entering the workforce, and the aging population all share one consequence; namely, they all increase demands placed on work and/or family, which leads to interrole conflict, and more specifically, work-to-family conflict and family-to-work conflict (Hammer \& Zimmerman, 2011). Role conflict is a central tenet of Role Theory. According to this theory, individual behavior is dictated by social norms and expectations that have been prescribed to specific roles (Kahn, Wolfe, Quinn, Snoek, \& Rosenthal, 1964). Inter-role conflict, in turn, is described as the psychological tension that arises when one is not able to fulfill the expectations of one role due to the competing demands of another, incompatible, role (Katz \& Kahn, 1978). Thus, work-to-family conflict (WTFC) is defined as the tension that arises when work demands impede the successful fulfillment of family demands, and is a form of inter-role conflict. Family-to-work conflict (FTWC), on the other hand, is operationalized as the tension that results from family demands hindering the satisfaction of work demands (Greenhaus \& Beutell, 1985). Research has shown that whereas work demands are most predictive of WTFC, family demands are most predictive of FTWC (Frone, Russell, \& Cooper, 1992).

Furthermore, the link between WTFC and FTWC with work related stress, family 
stress, job, life, and relationship satisfaction, as well as organization commitment, and performance, has been well established in the literature (e.g., Allen, Herst, Bruck, \& Sutton, 2000; Eby, Casper, Lockwood, Bordeaux, \& Brinley, 2005; Kossek \& Ozeki, 1998). A meta-analysis by Allen et al. (2000) reported moderate, positive effect sizes linking work-family conflict to several stress related outcomes, including general psychological strain $(r=.29)$, somatic/physical symptoms $(r=.29)$, depression, $(r=.32)$, alcohol abuse $(r=.13)$, burnout $(r=.42)$, work-related stress $(r=.41)$, and family-related stress $(r=.31)$, indicating that higher work-family conflict is related to increase healthrelated problems.

More directly relevant to this investigation, Allen et al. (2000) demonstrated an important negative relationships between work-family conflict and job satisfaction $(r=$ .23). Further, another meta-analysis with the specific focus of determining the relationship between work-family conflict and job/life satisfaction, found that WTFC negatively predicted job satisfaction $(r=-.27)$, and that this relationship was stronger for married $(r=-.29)$, and dual-earner couples $(r=-.37)$. Negative relationships were also reported between WTFC and life satisfaction $(r=-.35)$, but relationships for married individuals and those apart of a dual-earner couple were slightly less strong $(r=-.33)$. Likewise, FTWC had a negative overall relationship with job satisfaction, but this relationship was weaker than the WTFC and job satisfaction relationship $(r=-.14)$. Additionally, FTWC had a stronger relationship with life satisfaction than with job satisfaction $(r=-.25)$. Bi-directional conflict was also analyzed, and moderate relationships with both job $(r=-.31)$ and life $(r=-.29)$ satisfaction were reported. These findings have been supported by other, more recent, content and meta-analyses (Eby et 
al., 2005; Mesmer-Magnus \& Viswesvaran, 2005).

Conservation of Resources Theory (COR). Another theory focusing on the buffering effect of resources is the COR Theory (Grandley \& Cropanzano, 1999; Hobfoll \& Shirom 2001). Resources are said to come in four forms, 1) object resources (e.g., home, car), 2) condition resources (e.g., socioeconomic status, valued work position), 3) personal resources (e.g., self-efficacy, mastery), and 4) energy resources (e.g., money, time, credit). These resources are the means by which individuals achieve goals, and are therefore highly valued. Because resources are a precious commodity, individuals seek to maintain or gain them, and stress occurs when a person perceives that these resources are diminished. The work-family conflict - strain relationship has been shown to fit within this framework (Grandey \& Cropanzano, 1999; Wallace \& Chen, 2005). For example, Wallace and Chen (2005) suggest that work-family conflict arises when work demands begin to overtax the resources required to complete job tasks. Further, research has demonstrated that family- or home-related demands can consume resources that are needed to successfully perform at work (i.e., FTWC; Carlson, Kacmar, \& Williams, 2000; Lapierre \& Allen, 2006). Thus, COR theory posits that strain results from the conflict that arises when work or family demands deplete resources (Grandey \& Cropanzano, 1999; Lapierre \& Allen, 2006).

Social support. As mentioned briefly, one stress-buffering resource receiving abundant support in the literature is social support. A wealth of research has shown that the effectiveness of social support at reducing stress and increasing job satisfaction is undeniable (Lapierre \& Allen, 2006; Thomas \& Ganster, 1995; Viswesvaran, Sanchez, \& Fisher, 1999). Further, family-specific forms of support have been shown to be more 
effective at reducing WTFC and FTWC and improving health and job satisfaction than general forms of support (Hammer, Kossek, Yragui, Bodner, \& Hanson, 2009; Kossek, Pichler, Bodner, \& Hammer, 2011). Moreover, supervisors have shown to be especially important sources for decreasing WTFC and improving work and health outcomes (Berkman et al., 2010; Lapierre \& Allen, 2006; Thomas \& Ganster, 1995). Berkman et al. (2010) describe supervisors and managers as "the gatekeepers of [organizational] family responsive policies and practices," for their role in determining the levels of work-family strain that employees experience (p. 317). In this study, Berkman et al. (2010) found that employees with supervisors who were open, supportive, and creative about work-family needs (e.g., work schedule flexibility), slept 29 more minutes per day, and were over twice as likely to have 2 or more CVD risk factors than employees of supervisors who were less open, supportive, and creative. These findings suggest that not only are familyspecific forms of support especially important in organizations, but that supervisors ultimately hold the key to unlocking the door allowing support to have a positive effect. Further, research has shown that employee job satisfaction can be increased by family supportive supervision (Hammer et al., 2009; Hammer et al., 2011). Theory suggests that this is accomplished by decreasing workplace and family demands, role conflict, and the consequent strain associated with them.

Development of the FSSB construct. Hammer et al. (2009) developed and tested a measure that assesses family supportive supervisor behaviors (FSSB). This study revealed that FSSB was a multi-dimensional construct comprised of four sub-dimensions, 1) emotional support, 2) instrumental support, 3) role-modeling, and 4) creative work-life management. Emotional support involves the ability to understand and empathize with 
demands that employees face, and the willingness to listen to these challenges.

Instrumental support is related to supervisor support for creating solutions so that team members can meet their family and non-work demands. These may take the form of scheduling and flexibility. Role modeling behaviors refer to demonstrating how to balance work and family through modeling behaviors on the job. Creative work-family management refers to a supervisor's ability to create solutions that allow employees to meet both work and family demands.

The measure was found to have construct, criterion-related, and incremental validity, and FSSB was significantly related to work-family conflict, work-family positive spillover, job satisfaction, and turnover intentions over and above measures of general supervisor support (Hammer, et al., 2009). Another recent study using a sample of grocery store employees found that after training supervisors to be more familysupportive, the training was related to decreases in physical health and turnover intentions, and increases in job satisfaction for employees reporting high FTWC at baseline (Hammer, et al., 2011). In this study, training effectiveness was examined using Kirkpatrick's four level framework, assessing reactions (utility assessment), learning (pretest and posttest results in computer based training), behavior (self-reported behavior tracking over two-week period following training), and results (measure of influence of training on desired outcomes - i.e., health, turnover intentions, job satisfaction, WTFC). As the current investigation utilizes a training approach that is similar to the approach used by Hammer et al. (2011), it is important to note that the results of this evaluation were positive. For example, supervisors indicated that that they found the training to be useful, and a significant, positive difference was observed between mean pretest and 
posttest scores. Further, the goal tracking exercise revealed that FSSBs increased by $63 \%$ for number of times they were speak to employees and $107 \%$ for the number of times they would initiate a conversation about scheduling with employees.

Moreover, as mentioned, the training seemed to be beneficial for employees who reported high levels of FTWC at baseline, but not those who did not report high levels of FTWC at baseline. Finally, the training seemed to have negative effects for employees reporting low FTWC at baseline. Importantly, it may be that this disordinal interaction could be dissolved for highly adaptive supervisors who possess the sensibility to differentially utilize training knowledge based on individual employee needs. While not a focal interest in the present investigation, it may be worthwhile for future research to examine the influence of supervisor adaptability at reducing interactive effects so that FSSB training is a positive experience for all.

While the program of training-based research conducted by Hammer and colleagues, aimed at increasing FSSB, has shown promise, the influence of individual characteristics like personality, and specifically supervisor learning adaptability on differential training receptiveness and subsequent effectiveness, have yet to be tested. Given the vital nature of family supportive and safety supportive behaviors, and the crucial role that supervisors play in increasing positive employee outcomes, it is important that scientists and practitioners develop an understanding of what factors dictate training success, and the types of supervisors who would benefit most from training.

In sum, this research contributes to science by 1) exploring the nature of traitbased supervisor adaptability, and increasing the understanding regarding its validity and 
value, 2) exploring the link between trait-based learning adaptability and training effectiveness, 3) beginning to develop an understanding of the individual difference variables that predict FSSB training effectiveness, and 4) exploring the relationship between supervisor learning adaptability and employee job satisfaction. 


\section{CHAPTER 3}

\section{Hypotheses}

As shown in a previous section, dispositional and motivational characteristics have been shown to enhance training proficiency (Barrick \& Mount, 1991; Burke \& Hutchins, 2007). Among those characteristics receiving consistent support are openness to experience, extraversion, and proactive personality (Barrick \& Mount, 1991; Burke \& Hutchins, 2007; Fuller \& Marler, 2009). For example, Major et al. (2006) demonstrated that openness to experience, extraversion, and proactive personality were linked to motivation to learn, which predicted development activity. Although learning adaptability, motivation to learn, and openness to experience are distinct constructs, they all share a unique component, specifically, they reflect a trainee readiness to participate in learning experiences. No research to date has explored the role of trait-based learning adaptability on training effectiveness, especially within the context of an evidence-based work-family supervisory training program (Hammer et al., 2011). A model depicting all of the relationships hypothesized can be seen in Figure 1.

Hypothesis 1: The training will predict six month FSSB, such that supervisors in the treatment group will have higher employee reports of FSSB post training than supervisors in the control group.

Hypothesis 2: Supervisor learning adaptability will moderate the relationship between training and employee reported FSSB, such that the positive relationship between the training and six-month employee-reported FSSB will be stronger when supervisor learning adaptability is high. 
Finally, given that past research has shown that training supervisors in FSSB led to increases in employee job satisfaction (Hammer et al., 2011), it is plausible to expect that highly adaptive supervisors will learn and implement FSSB more successfully, thereby decreasing employee role conflict related strain, and increasing job satisfaction.

Hypothesis 3: The training will predict six-month employee job satisfaction, such that employees in the treatment group will have higher employee job satisfaction post training than employees in the control group.

Hypothesis 4: Supervisor learning adaptability will moderate the relationship between training and employee job satisfaction, such that the positive relationship between the training and six-month ratings of employee job satisfaction will be stronger when supervisor learning adaptability is high. 


\section{CHAPTER 4}

\section{Method}

\section{Design and Overview}

The present study used a training program called The Safety and Health Improvement Program (SHIP), which is designed to promote physical and mental health, safety communication, and reduce work-family conflict by improving supervisor support for both family and safety, and increasing team communication processes and effectiveness. This research was conducted as part of the Oregon Healthy Workforce Center, which is one of four Total Worker Health ${ }^{\mathrm{TM}}$ Centers for Excellence, and is funded by the National Institute for Occupational Safety and Health (NIOSH). Although all team members went through the Team Effectiveness Process (TEP) training, supervisors were given additional, computer-based training (called cTRAIN), that provided insight into the importance of recognizing employee's family life, and taught skills and behaviors that were focused on successful integration of work and family. The training also focused on increasing safety-related communication from supervisors and within teams. The TEP training focused on ways that teams can eliminate low value work and focus on essential tasks, leaving more energy to focus on safety and positive workfamily management behaviors. To enhance the transfer of supervisor training, supervisors tracked supervisor family-supportive behaviors and safety-related communication behaviors using an iOS application on iPod Touch devices that were lent to supervisors during a two-week period (Olson et al., 2009). Many of the supervisors that participated in this training have been with their respective organizations for a long period of time, many for over 15 years. With such long tenures it may be fair to assume that 
organizational change on such a grand scale may prove to be a difficult challenge for some. This training necessitated learning new skills, and implementing daily behavioral changes that required proactivity, especially on the part of the supervisors. Blindl and Parker (2010) define proactive work behavior as "self-starting, future-oriented behavior that aims to bring about change in one's self or the situation" (p. 2). Furthermore, due to the nature of the family supportive supervisor behavior (FSSB) portion of the training, these learned behaviors may require some supervisors to connect with their team members on a much deeper emotional and personal level.

Data for this study were collected at baseline and six months post-intervention.. Prior to beginning any data collection, supervisors were randomly assigned into either a waitlist-control group or an intervention group. The sample consisted of 23 supervisors and their 291 employees.

\section{Participants}

Participants were taken from a sample of construction and field workers in two independent municipal public works agencies in a city in the northwest United States. Recruitment was accomplished by first obtaining support at the organizational level. Existing relationships between principal investigators and both the Union, AFSCME Local 189, and management interest in increasing safety and family specific support at the organization facilitated the introduction of the project intervention at the worksite. Organizational leaders mandated training for supervisors, and all study participation took place during paid company time. Work groups were randomly assigned to either control or treatment conditions (treatment teams, $k=14$; control teams, $k=9 ; n=291$ employees, and $n=23$ supervisors). Teams consisted of one supervisor and roughly ten 
employees, on average. Participants were predominantly white males, with a mean age of 44. Sample characteristics can be found in Table 2. Participants in this study were part of a larger, randomized control trial, to test the effects of the SHIP intervention on several other organizational and health outcomes.

\section{Procedures}

First, both employees and supervisors completed a paper-and-pencil survey containing measures of FSSB (Hammer et al., 2009) and job satisfaction (Hackman \& Oldham, 1975) at baseline, six months, and twelve months post-training. Unfortunately, supervisor learning adaptability was not measured at baseline, but rather at six months and twelve months, post training. While these twelve-month data were not used for hypothesis testing, the value of retaining this measure at twelve-month follow-up, and a discussion regarding the implications of not measuring adaptability at baseline, will be discussed in a later section. While two forms of FSSB measures were included in the survey (one in which employees rated the FSSB of their supervisors, and one in which supervisors rated their own perceived FSSB), I only used the employee-rated FSSB version. Participation in the survey was voluntary, but employees were incentivized with a \$25 gift card at all time-points. Surveys were completed at the beginning of the workday before leaving for the field, took place on company time, and took roughly 30 minutes to complete.

Shortly following completion of the survey at baseline, supervisors participated in mandatory computer-based training, called cTRAIN. The cTRAIN platform, developed by Anger and colleagues (Anger et al., 2001), is an evidenced based training, completed via interactive software that provides insight into the importance of recognizing 
employee's family life, and teaches skills to provide various forms of support for employee's family life. The training also highlighted the importance of exhibiting safety supportive behaviors, as well as taught skills to provide safety support. The self-directed software utilized a platform that allows users to move at their own pace, go back to previous sections, and involved taking quizzes to test knowledge gained throughout the exercise. At the beginning of the training, supervisors were given an overview of content they would be expected to learn and a pre-test. Content was delivered via lecture and video, with the option of reading text or listening with headphones as the content is read aloud. Prior to beginning the training, a research assistant briefed supervisors on training and organizational goals, as well as aided them in commencing training. The training took approximately 30-45 minutes to complete, and one or more research assistants were present to answer any questions that supervisors may have had during training.

Directly following the training, supervisors were assigned an iPod Touch loaded with a behavior tracking application, called habiTRAK (Olson \& Winchester, 2008). This application contained information that summarized key-points learned during training, and allowed supervisors to set and track training related goals over a two-week period. To aid supervisors in understanding this process, a trained-research assistant communicated one-on-one with the supervisor, prompting him/her to set their own goals (emphasizing that goals be challenging, yet achievable), as well as showed them how to track behaviors and record goal progress. Goal tracking was done by entering a screen that listed specific family support-related behaviors, and tapping on a portion of the screen that corresponded to the behavior. Supervisors were prompted by an alarm on the device twice during the workday to track behaviors that occurred during that workday. 
The supervisor selected these alarm times during the one-on-one instruction, according to individual discretion of when tracking goals would least interfere with other job tasks. Goal tracking progress was recorded to the device, and entered into a database when the iPods were returned. Shortly following the goal-tracking period, a follow-up session with all supervisors was completed to give a report of the aggregated results. Additionally, supervisors were privately given a paper report of their individual goal tracking behaviors during the two-week period. At the follow-up session, supervisors were given the opportunity to voice feedback about cTRAIN, and the behavior tracking exercise. Session facilitators took notes of this supervisor-generated feedback.

In addition to the cTRAIN and behavior tracking exercise, supervisors and their teams went through a team effectiveness process (TEP) training, developed by Work Family Directions, a consulting firm that specializes in work-family integration practices within organizations. This training was mandatory and involved participation in a fourhour long, facilitator-led session that focused on ways that teams can eliminate low value work and focus on essential tasks, leaving more energy to focus on safety and positive work-family management behaviors. Employees also completed assessments of team processes that were linked to their supervisors and involved questions regarding practices used in their crew or team that fostered good morale, communication, teamwork and flexibility, as well as work-life integration, and identified areas of inefficiency. The TEP training also highlighted work/life effectiveness operating principles, which were agreements and ground rules between team members regarding how they would work together to achieve the desired work environment, enhancing teamwork, communication, flexibility and work/life effectiveness. These behavioral statements served as a reminder 
of what the team was striving for and a roadmap for success, and were revisited by the team throughout the year. The TEP training also involved follow-up sessions at 30, 60, and 90 days, which involved facilitator-led team discussions about progress toward team goals (for a brief description of my personal role in data collection, please refer to the Appendix).

\section{Measures}

Supervisor adaptability. The I-ADAPT-M is a measure developed by Ployhart and Bliese (2006) assessing eight dimensions of individual adaptability, and consists of 55 items. In this study, I only used the 9 items that assess learning adaptability. The IADAPT-M has been shown to have convergent and discriminant validity (Hamtiaux et al., 2013), and had reliability estimates of $\alpha=.88$ for six months and $\alpha=.89$ at twelve months for supervisors $(n=23)$. Adaptability is assessed on a 1 to 5 Likert scale, with 1 indicating low adaptability and 5 indicating high adaptability. The items for all survey items are listed in Table 1.

Family Supportive Supervisor Behaviors. Family Supportive Supervisor Behaviors (FSSB) were assessed using the FSSB-Short Form (FSSB-SF; Hammer, Kossek, Bodner, \& Crain, 2013). The FSSB-SF is a condensed version of a 14-item measure, assessing the four dimensions of FSSB (Hammer et al., 2009). The FSSB-SF retains one item from each dimension, which are assessed on a 1 to 5 Likert scale, 1 indicating lower FSSB, and 5 indicating high FSSB. A Confirmatory Factor Analysis, and regression analyses have demonstrated that the scale possesses construct and criterion validity, and with reliability estimates of $\alpha=.91$ at baseline, and $\alpha=.92$ at six months within the present sample of employees $(n=291)$. 
Employee job satisfaction. Employee job satisfaction was assessed using a 3item measure assessing global satisfaction with the job on a 1 to 5 Likert scale, with 1 indicating low job satisfaction, and 5 indicating high job satisfaction (Hackman \& Oldham, 1975). Reliability estimates for this sample of employees $(n=291)$ were $\alpha=.87$ at baseline and $\alpha=.82$ at six months.

Covariates. Demographic variables (age, gender, education, and marital status) as well as organizational tenure, number of children, and number of hours worked per week were originally used as covariates because research has shown that they may have relationships with the outcomes (Hammer et al., 2009; Lee \& Wilbur, 1985). However, within this sample, only age and occupational tenure were ultimately used for hypothesis testing because they were the only variables that correlated with either the outcome variables or the predictor variables (in this case, both significantly related to supervisor learning adaptability).

Because data were collected from two independent public works agencies, analyses were also conducted independently in each organization due to qualitative differences that were observed by researchers in organizational culture, and potential differences in organizational acceptance of the training. However, statistical power was further diminished in these analyses due to reduced sample sizes, and therefore yielded non-significant findings in both organizations. Therefore, ultimately, hypothesis testing was conducted on the combined sample of both organizations. Nevertheless, because these qualitative differences in training acceptance and organizational culture were observed, it was important to also control for organizational affiliation (i.e., industry) in the analyses that follow. Further, as the study was interested in assessing the effect of the 
intervention and supervisor learning adaptability on six-month FSSB, and six-month employee job satisfaction, baseline levels of both FSSB and employee job satisfaction were controlled for in hypothesis testing where applicable. 


\section{CHAPTER 5}

\section{Results}

\section{Preliminary Analyses}

Descriptive statistics were computed to detect sample characteristics (e.g., demographic variables), patterns of missing data, and variable outliers. Bivariate correlations between study variables and time points were also used to estimate the nature of their relationships. Sample characteristics can be found in Table 2. It is important to note that for all analyses, both organizations were combined into a single sample, and organizational affiliation was controlled for where applicable.

Study Correlations. Bivariate correlations between covariates and primary study variables can be found in Table 3 for both supervisors (above the diagonal) and employees (below the diagonal). This table demonstrates that in the sample of employees, learning adaptability relates to expected variables in expected directions. For example, employee-level six-month learning adaptability significantly and negatively correlated with age $(r=-.13)$ and occupational tenure $(r=-.21)$, and it significantly and positively correlated with FSSB $(r=.24 ; r=.21)$ and employee job satisfaction $(r=.22 ; r=.36)$ at both baseline and six months, respectively. Within the supervisor sample, however, learning adaptability only significantly correlated with age $(r=-.44)$ and job satisfaction at baseline $(r=.43)$, likely due to low statistical power, but these relationships remained in the expected directions. Because the aim of this study was the cross-level interaction between supervisor learning adaptability and employee-level outcomes, the aforementioned correlations at the employee-level and supervisor-level are not particularly germane to the present study. Rather, they serve to inform the reader that, 
given more statistical power, learning adaptability as a construct may have value.

Further, these relationships help to increase understanding and expand the nomological network of the adaptability construct.

Cross-level correlations are contained in Table 3 (i.e., supervisor learning adaptability at six- and twelve-months, and employee-level variables). Again, due to low statistical power, six-month supervisor learning adaptability was not significantly related with any employee-level variable, whereas twelve-month supervisor learning adaptability was significantly correlated with both employee-reported FSSB at baseline $(r=.24)$ and six months $(r=.23)$.

Learning Adaptability Factor Structure. Because learning adaptability is a fairly new construct, an Exploratory Factor Analysis (EFA) and a Confirmatory Factor Analysis (CFA) were conducted to test the factor structure of the measure within this sample. It is important to note that because supervisor learning adaptability is the focus of this investigation, ideally, any test of construct validity should also be assessed on a sample comprised solely of supervisors. Specifically, as the hypothesized relationships involve supervisor learning adaptability as a moderator on study outcomes, an investigation of this measure's reliability and validity within the sample of supervisors is prudent. Unfortunately, with only 23 supervisors, statistical power is diminished substantially enough to make such an investigation meaningless. Therefore, I have used the entire sample of supervisors and employees $(N=314)$ to assess construct validity. The results from these tests should be interpreted with caution, and bare little importance to present hypothesis testing, but serve to expand on the nomological network of individual adaptability. 
For the EFA using the combined supervisor and employee sample, Oblimin rotation was used. Results from the EFA showed that five items loaded onto a single factor, three items loaded onto another factor, and a single item loaded onto both factors, but neither very strongly. Results from the EFA can be found on Table 4. The CFA conformed to these findings. Based on the Chi-square test, we see that the test is significant $\left(\chi^{2}=223.74, p<.01\right)$ indicating that the learning adaptability scale measured more than one factor in this sample. Further, the Comparative Fit Index (CFI) and the Root Mean Square Error of Approximation (RMSEA) coefficients (.88 and .12, respectively) also confirm that a single factor model does not fit the data. Based on these results, scale scores were computed from both the five items that loaded onto a single factor and the full nine-item scale. Further, hypothesis testing was done using both the five-item scale and the original nine-item scale. No dramatic differences were observed between the results using either scale in terms of directionality or significance values. As such, I have reported the results using the full nine-item scale as other studies have confirmed a single factor structure with the whole scale (Hamtiaux et al., 2013; Wang et al., 2011).

Statistical power. In order to detect likelihood of committing type II error in hypothesis testing, I evaluated statistical power using Optimal Design for Multilevel and Longitudinal Research (ODMLR) Version 3.01 software (Raudenbush, Spybrook, Congdon, Liu, \& Martinez, 2011). In estimating power, I used the approach of evaluating likelihood of committing a type II error by plotting the expected intraclass correlation (ICC) by number of supervisors and employees nested within supervisor. Based on previous studies conducted by Hammer and colleagues $(2009 ; 2011)$ examining 
employees nested within supervisors in a common geographically limited organization, I expected an ICC of $<.05$. Thus, setting the ICC at .05 , expecting to detect a modest effect size of .3, and using a sample of 291 employees nested within 23 supervisors, estimated power was .58. Results from the power analysis reveal that this study does not reach a level of statistical power that is typically considered ideal (e.g., often .80; Tabachnick \& Fidell, 2013). Results from power analyses can be found in Figure 2. Missing data. To account for missing values in the dataset, the default approach in SPSS is listwise deletion. This approach involves the automatic removal of cases where data are missing. Tabachnick and Fidell (2013) recommend this approach when there are only a few missing data values. When participants have filled out at least $75 \%$ of the items contained in a measure, another approach to dealing with missing values involves computing a scale score from a combination of the completed items, supplemented by a computed mean for the missing items. (This mean is computed from values provided by the individual for the majority of the measure, as long as those values account for at least $75 \%$ of the items in the scale.) This approach is useful because while most participants who fill out at least $75 \%$ of a measure typically complete the entire measure, a select few will neglect a single item from a measure while completing the rest of the items. Because scale scores are computed from individual items, a listwise deletion approach would eliminate such participants entirely from analysis. For this investigation, I have elected to use this mean imputation approach where appropriate, noting that missing data are not a significant problem in this dataset. Further, I tested the hypotheses by analyzing data using both a listwise deletion approach, and using scales computed with mean imputation, and noted no dramatic differences in results. Thus, for the 
integrity of the data, I have proceeded with listwise deletion where participants filled out less than $75 \%$ of a given measure, and mean imputation where participants filled out $75 \%$ or more of a given measure.

\section{Hypothesis Testing}

As the supervisor adaptability measures were assessed at the supervisor level (i.e., self-assessment), and the FSSB and employee job satisfaction measures were assessed at the employee level, general linear mixed modeling analysis techniques were employed for hypothesis testing, with work group as the nesting variable for all hypotheses. An intercepts-only model (IOM; Table 5) and intraclass correlations were computed to test nesting effects for both outcomes, six-month FSSBs and six-month employee job satisfaction. The ICCs for six-month employee reported FSSBs and six-month employee job satisfaction were .03 and .01 , respectively. As the relationship between FSSB-based training and subsequent increases in job satisfaction has been established (Hammer et al., 2011), hypothesis one served to bolster evidence for this relationship. Further, for all hypothesis testing, age, organizational tenure, industry (organizational affiliation), and baseline levels of the outcome variable were used as control variables. Results from hypothesis one, whether or not the training predicted an increase in employee-reported FSSB, showed that group assignment (i.e., training group vs. control group) did not significantly predict six-month employee reports of FSSBs $(\beta=.01, p=.96)$. Thus, hypothesis 1 was not supported (see Table 6). To test the moderating effect of supervisor learning adaptability in this relationship, an interaction term between supervisor learning adaptability and the treatment indicator variable was computed after mean centering both variables, and then entered into the model. Results from this test showed that supervisor 
adaptability did not significantly moderate the relationship between the training and six-month employee reported FSSBs $(\beta=-.14, p=.66)$, showing no support for hypothesis 2 (see Table 7). To test hypothesis 3 and 4, a similar analytic approach was employed, but exchanging six-month employee-rated FSSBs with six-month employee job satisfaction as the outcome variable, as well as controlling for baseline employee job satisfaction. The training did not significantly predict six month employee job satisfaction $(\beta=-.03, p=.62)$, and this relationship was not moderated by supervisor learning adaptability $(\beta=-.22, p=.19)$. Thus, hypotheses 3 and 4 were also not supported (see Tables 8 and 9 , respectively). A summary of results and discussion regarding supplemental analyses, not part of the hypothesized model, are included in the discussion section. 


\section{CHAPTER 6}

\section{Discussion}

\section{Primary Findings}

The present study explored the role of a training aimed at increasing supervisor family- and safety-related supportive behaviors, and improving team effectiveness, on increasing employee-reported FSSB and employee job satisfaction at the six-month follow-up. The study also sought to explore the moderating role of supervisor learning adaptability on these relationships. Ultimately, the study did not find the training to predict six-month FSSB or employee job satisfaction. Further, the study failed to show that supervisor learning adaptability had a moderating impact on these relationships. In sum, none of the hypotheses were supported. The most likely explanation for the nonsignificant findings lies with low statistical power. As discussed previously, testing a cross-level interaction with only 23 supervisors yielded a power estimate of .58 , falling far below recommended levels (Tabachnick \& Fidell, 2013). Additionally, supervisor learning adaptability held the lowest measurement variability of all primary study outcomes at six months $(M=3.75, S D=.39)$ further reducing statistical power in this sample. For a comparison between all primary variable means and standard deviations, see Table 10.

\section{Supplemental Analyses}

Because all outcome variables were also assessed at twelve-months, I ran the same general linear mixed models used in hypothesis testing, to explore the role of the training, and the moderating role of supervisor learning adaptability on twelve month employee-reported FSSB and employee job satisfaction. Results from these analyses also 
yielded non-significant findings. Additionally, as the sample was too small to adequately test hypothesized relationships, I ran the same models at the individual level on the entire sample $(N=314)$, ignoring cross-level interactions. While not the focus of this study, the justification for these analyses is simple: all employees went through some form of training. While supervisors completed additional training, both supervisors and employees participated in TEP training. Thus, it is conceivable that learning adaptability for the entire sample moderated the relationship between training and job satisfaction, generally. Unfortunately, these tests also yielded non-significant findings for all models. I was also interested in examining the direct effect of supervisor learning adaptability on employee-reported FSSB and job satisfaction at six months and twelve months separately by group assignment (treatment, and then control). The majority of these results were also non-significant with one exception. Oddly, supervisor learning adaptability was significantly related to increased six-month employee job satisfaction ( $\beta$ $=.24, p<.05)$, but only in the control group. Because I have established that this sample lacks adequate statistical power for cross-level interactive effects, I tested the direct effects of learning adaptability on employee-reported FSSB and job satisfaction (six and twelve months) at the individual level for the entire sample (while still controlling for work group) separately by group assignment (treatment, and then control). These tests showed that six-month learning adaptability predicted six-month job satisfaction $(\beta=.24$, $p<.01)$ and twelve-month job satisfaction $(\beta=.30, p<.01)$ in the treatment group. These significant direct effects of learning adaptability on six and twelve month job satisfaction were not observed in the control group. This finding gives credence to the possibility that learning adaptability may, in fact, have a moderating influence in a 
training context, given ample sample sizes and adequate statistical power. These significant findings, in conjunction with the significant correlations outlined in Table 3 , also confirm theoretical assumptions about individual adaptability, adding to construct validity and the nomological network, namely, that learning adaptability is related to job satisfaction and effective supervision (specifically with regard to family support).

While Ployhart and Bliese (2006) theorize that individual adaptability is stable and trait-like, to my knowledge, this had yet to be empirically tested. Therefore, to test the stability of the construct, I ran t-tests for the learning adaptability measure between treatment and control groups at six months, and between six and twelve months for the entire sample. Because the construct is assumed to be trait-like, there should have been no differences between treatment and control groups at six months, or between scores measured at six months and scores measured at twelve-months. Findings from these ttests were non-significant and confirmed the stability assumption $(t=-.17, p=.87)$, and $(t=-.77, p=.44)$, respectively. These tests of measure stability also add to the nomological network by providing empirical support for the claim that individual adaptability is, in fact, stable as theorized.

\section{Practical Contributions}

While none of the hypotheses were supported, this research still has some theoretical and practical contributions. First, an examination of study correlations shows that learning adaptability is significantly related to expected variables and in the expected directions. For example, while the moderating effects of supervisor adaptability were not significant (possibly due to insufficient statistical power), learning adaptability for the whole sample (employees and supervisors, combined) was still positively related to 
employee-rated FSSBs and employee job satisfaction. This shows that employees and supervisors with high learning adaptability have higher job satisfaction than those employees and supervisors lower on learning adaptability. Moreover, highly adaptable employees and supervisors rate their supervisors as being more supportive of their family life.

These findings are important for two reasons. First, while organizations should aim to have family-supportive policies, and a culture of supportive supervision, it may be that some employees need more support and guidance than others. Specifically, employees high in learning adaptability may be more prepared to learn about an organization's policies and how to take advantage of them, thereby increasing perceptions of support. Meanwhile, another employee with low levels of learning adaptability could be struggling to find support he/she needs. Organizations could use the learning adaptability measure to assess which individuals may need special attention and direction in terms of how and when to use available supportive systems that are in place.

Interestingly, learning adaptability was negatively correlated with age and occupational tenure. Within this sample, it would seem that older workers and workers with longer tenures rate themselves as being lower on learning adaptability. This conforms to research demonstrating that career learning and development declines as workers age (Maurer, 2001). This has practical implications if organizations hope to implement trainings that involve older workers or those who have spent a great deal of time working within the organization. For example, it may be that older workers and those with long organizational tenures require an additional, pre-training, in order to more adequately prepare them to engage in learning experiences. These correlational 
relationships can be found on Table 3 .

\section{Theoretical Implications}

This investigation also served to increase theoretical knowledge about the largely ignored individual adaptability measure. The study established new relationships between learning adaptability, job satisfaction, age, occupational tenure, and FSSB. It further explored construct validity with a new sample by running confirmatory and exploratory factor analyses. A final contribution of this study was in empirically testing and confirming the stability of the adaptability trait. While Ployhart and Bliese (2006) theorized that adaptability was a stable trait, this had yet to be empirically tested. However, because no significant differences were observed between treatment and control groups or from six months to twelve months in this study, this lends empirical support to the theoretical claim that learning adaptability is, in fact, stable and trait-like. In conclusion, while none of my hypotheses were supported, this investigation still adds value by improving the understanding surrounding trait-based adaptability and increasing the nomological network.

\section{Limitations and Future Directions}

This investigation is not without limitations. First, the study hypothesized that supervisor learning adaptability influences FSSB training effectiveness by increasing motivation to learn. However, a measure of motivation to learn was not included. Thus, unfortunately, this theoretical relationship could not be tested. Further, survey size constraints restricted the use of other adaptability facets that could potentially be related to training effectiveness. Learning adaptability was chosen based on the assumption that it was the most relevant to this study, not because it was the only facet of individual 
adaptability that could theoretically relate to training effectiveness. Specifically, given the similarity between creative work-life management (a facet of FSSB) and creative adaptability, it is conceivable that this trait would also explain variance in study outcomes. For example, creative work-life management requires being flexible and inventive in order to discover solutions to restructure work in ways that accommodate unique employee needs that facilitate employee effectiveness on and off the job (Hammer et al., 2009). Thus, it is conceivable that supervisors with high levels of creative adaptability would be more aptly prepared to handle these unique work-life challenges.

Further, work-stress adaptability, uncertainty adaptability, and crisis adaptability could potentially predict training effectiveness due to the uncertainty and stress associated with organizational change (Wang et al., 2011), and the fact that many workplace crises are intertwined with events that occur outside work (Eby et al., 2005). Due to these limitations, future research should explore other dimensions of adaptability and motivation to learn in a variety of organizations and training contexts.

As discussed at length in previous sections, estimates of low statistical power also present a limitation to the analysis. In this study, a power estimate of .58 was calculated, indicating a greater likelihood of committing type II error, or the failure to reject the null hypothesis when it is false. Thus, although none of the hypothesized relationships received support in this study, it is plausible that with a larger sample, significant results could have been found. Future research should examine the role of adaptability in training contexts with adequate sample sizes and diverse populations.

A final limitation is that I did not measure adaptability at baseline. Although adaptability is theorized to be a stable-trait, this had yet to be empirically demonstrated 
prior to this study. Zapf, Dormann, and Frese (1996) have recommended that all variables should be measured at all time points in longitudinal research. Therefore, future research should heed this counsel to strengthen conclusions based on future findings.

Future research should also explore the malleability of the individual-adaptability construct. In other words, researchers should explore if and how adaptability can be learned, strengthened, or even diminished. While personality traits are said to be stable, research has shown that personality does in fact change over the life-span, and under certain circumstances (Caspi, \& Roberts, 2001; Roberts, Walton, \& Viechtbauer, 2006). While Ployhart and Bliese (2006) do not explicitly call individual-adaptability a personality trait, they hypothesize that it is determined directly by knowledge, skills, abilities, and other characteristics (KSAOs; considered stable), as well as personality, stating that "adaptability is still reasonably stable and trait like. However, it is more malleable than the KSAOs because it can be learned and changed to a degree (please note - while malleable, it is not easily changeable and thus more distal than proximal)." (p. 17). Although Ployhart and Bliese make the statement that it can be learned, they fail to elaborate how such a thing is accomplished.

Additionally, if adaptability can be learned (e.g., increased), this begs the question, are there circumstances that occur in an environment that could potentially diminish individual adaptability over time? For example, if an employee were exposed to several, poorly administered, and ineffective trainings over time, would this individual's desire, willingness, and ability to engage in learning activities decrease over time (i.e., his/her levels of learning adaptability), given his/her experience that organizational mandated trainings simply do not work, and are a waste of time. 
Despite the fact that this study failed to find a moderating effect of learning adaptability on training effectiveness due to insufficient statistical power, it makes logical sense that, given the right context, the right training, and ample sample sizes, learning adaptability may moderate training effectiveness. If future research confirms this assumption, it would be important to know how malleable the construct is, and how one might hope to increase learning adaptability in training participants who are found to have low levels of learning adaptability prior to training, in order to increase trainee readiness, and improve subsequent training outcomes. Therefore, future research should explore these questions and elaborate on the malleability of the adaptability construct.

In conclusion, although this study did not find support for the hypothesized model (see Figure 1), correlational findings at the individual level, supplemental analyses between treatment and control groups, and tests of measure stability and validity, all aid to bolster the nomological network for the construct of individual adaptability. Individual adaptability is still a fairly under-used construct, despite its apparent utility in a variety of organizational contexts. Lastly, this study demonstrates the need for future investigation involving the construct of individual-adaptability. 
Tables and Figures

Table 1

Survey Items

Item Construct

1. I take responsibility for acquiring new skills

Learning Adaptability

2. I enjoy learning new approaches for conducting work

Learning Adaptability

3. I take action to improve work performance deficiencies

Learning Adaptability

4. I often learn new information and skills to stay at the forefront of

Learning Adaptability my profession

5. I quickly learn new methods to solve problems

Learning Adaptability

6. I train to keep my work skills and knowledge current

Learning Adaptability

7. I am continually learning new skills for my job

Learning Adaptability

8. I take responsibility for staying current in my profession

Learning Adaptability

9. I try to learn new skills for my job before they are needed.

Learning Adaptability

1. My supervisor makes me feel comfortable talking to him or her

FSSB about my conflicts between work and nonwork.

2. My supervisor works effectively with workers to creatively solve

FSSB conflicts between work and nonwork.

3. My supervisor demonstrates effective behaviors in how to juggle

FSSB work and nonwork issues.

4. My supervisor thinks about how the work in my department can

FSSB be organized to jointly benefit employees and the company.

1. In general, you like working at your job

Job Satisfaction

2. In general, you are satisfied with your job

Job Satisfaction

3. You are generally satisfied with the kind of work you do in this

Job Satisfaction job 
Table 2

Sample characteristics

\begin{tabular}{|c|c|c|c|c|}
\hline & Frequency & Percent & Mean & $S D$ \\
\hline Gender & 281 & 99.6 & & \\
\hline Male & 251 & 89 & & \\
\hline Female & 30 & 10.6 & & \\
\hline \multicolumn{5}{|l|}{ Race } \\
\hline White, Non-Hispanic & 212 & 75.2 & & \\
\hline American Indian Or Alaskan Native & 9 & 3.2 & & \\
\hline $\begin{array}{l}\text { Black Or African American, Non- } \\
\text { Hispanic }\end{array}$ & 18 & 6.4 & & \\
\hline Asian Indian & 9 & 3.2 & & \\
\hline Other Pacific Islander & 1 & .4 & & \\
\hline Some Other Race & 7 & 2.5 & & \\
\hline Hispanic & 7 & 2.5 & & \\
\hline More Than One Race & 22 & 7.8 & & \\
\hline \multicolumn{5}{|l|}{ Education } \\
\hline $\begin{array}{l}\text { Grade } 9 \text { Through } 11 \text { (Some High } \\
\text { School) }\end{array}$ & 5 & 1.8 & & \\
\hline $\begin{array}{l}\text { Grade } 12 \text { Or Ged (High School } \\
\text { Graduate) }\end{array}$ & 105 & 37.2 & & \\
\hline $\begin{array}{l}\text { College } 1 \text { - } 3 \text { Years (Some College } \\
\text { Or Technical School) }\end{array}$ & 132 & 46.8 & & \\
\hline $\begin{array}{l}\text { College } 4 \text { Years Or More (College } \\
\text { Graduate) }\end{array}$ & 34 & 12.1 & & \\
\hline Attended Graduate School & 3 & 1.1 & & \\
\hline \multicolumn{5}{|l|}{ Marital Status } \\
\hline Single & 60 & 22 & & \\
\hline Married/Living & 216 & 78 & & \\
\hline \multicolumn{5}{|l|}{ Org Role } \\
\hline Supervisor & 27 & 9.9 & & \\
\hline Crew Leader & 50 & 18.2 & & \\
\hline Crew Member & 178 & 65.0 & & \\
\hline Other & 19 & 6.9 & & \\
\hline \multicolumn{5}{|l|}{ Condition } \\
\hline Treatment & 188 & 31.6 & & \\
\hline Control & 89 & 66.7 & & \\
\hline \multicolumn{5}{|l|}{ Industry } \\
\hline Org 1 & 187 & 66.3 & & \\
\hline Org 2 & 95 & 33.7 & & \\
\hline Organizational tenure & 276 & & 10.88 & 8.05 \\
\hline Age & 281 & & 44.46 & 9.84 \\
\hline Work hours per week & 262 & & 41.23 & 8.74 \\
\hline Number of children & 163 & & 1.91 & .89 \\
\hline
\end{tabular}


Table 3

Bivariate correlations for employee $(n=291)$ and supervisor $(n=23)$ samples

\begin{tabular}{|c|c|c|c|c|c|c|c|c|}
\hline & Age & Tenure & FSSB BL & FSSB 6M & Job Sat BL & Job Sat 6M & LA $6 \mathrm{M}$ & LA $12 \mathrm{M}$ \\
\hline Age & - & $.45 *$ & .18 & .12 & -.06 & .08 & $-.44 *$ & $-.60 *$ \\
\hline Tenure & $.53 * *$ & - & -.17 & -.25 & .08 & .22 & -.35 & $-.68 * *$ \\
\hline FSSB BL & -.04 & -.08 & - & .34 & .40 & .33 & -.01 & -.21 \\
\hline FSSB 6M & -.04 & -.06 & $.58 * *$ & - & .30 & $.48^{*}$ & .12 & .30 \\
\hline Job Sat BL & -.05 & -.03 & $.27 * *$ & $.28 * *$ & - & $.81 * *$ & $.43^{*}$ & .15 \\
\hline Job Sat $6 \mathrm{M}$ & -.01 & -.08 & $.25 * *$ & $.39 * *$ & $.74 * *$ & - & .27 & .09 \\
\hline LA $6 \mathrm{M}$ & $-.13 *$ & $-.21 * *$ & $.24 * *$ & $.21 * *$ & $.22 * *$ & $.36^{* *}$ & - & .87 \\
\hline LA $12 \mathrm{M}$ & $.20 * *$ & $-.27 * *$ & $.25 * *$ & $.20 * *$ & $.15^{* *}$ & $.18^{* *}$ & $.68 * *$ & - \\
\hline
\end{tabular}

Note. $*$ Indicates significance at the $p<.05$ level, and **indicates significance at the $p<.01$ level. Supervisor $(n=23)$ correlations provided above the diagonal, and employee level $(n=291)$ correlations provided below the diagonal. $\mathrm{BL}=$ baseline or time $1 ; 6 \mathrm{M}=6 \mathrm{month}$ follow-up or time $2 ; 12 \mathrm{M}=12$ month follow-up or time 3 ; LA = learning adaptability. 
Table 4

Exploratory Factor Analysis (EFA) results

\begin{tabular}{lcr}
\hline & \multicolumn{2}{c}{ Factor } \\
\cline { 2 - 4 } & 1 & 2 \\
\hline I take responsibility for staying current in my profession. & .84 & -.04 \\
I often learn new information and skills to stay at the forefront of my & .82 & .06 \\
profession. & & -.01 \\
I train to keep my work skills and knowledge current. & .82 & -.04 \\
I am continually learning new skills for my job. & .78 & .00 \\
I try to learn new skills for my job before they are needed. & .74 & .16 \\
I quickly learn new methods to solve problems. & .49 & .97 \\
I enjoy learning new approaches for conducting work. & -.14 & .62 \\
I take responsibility for acquiring new skills. & .14 & .58 \\
I take action to improve work performance deficiencies. & .16 & \\
\hline
\end{tabular}

Note. Extraction Method: Principal Axis Factoring. Rotation Method: Oblimin with Kaiser

Normalization.

Table 5

Intercepts only models for study outcome variables

\begin{tabular}{|c|c|c|c|c|c|}
\hline $\begin{array}{l}\text { Outcome } \\
\text { Variable }\end{array}$ & $\beta$ & $S E$ & $d f$ & $t$ & $p$ \\
\hline FSSB 6M & .33 & .06 & 34.45 & 51.26 & .00 \\
\hline Job Sat $6 \mathrm{M}$ & 3.93 & .04 & 24.96 & 90.68 & .00 \\
\hline
\end{tabular}

Table 6

Multilevel model results for hypothesis one, the effect of the training on six month employee reported FSSB

\begin{tabular}{lrrrrr}
\hline \multicolumn{1}{c}{ Parameter } & $\beta$ & $S E$ & $d f$ & $t$ & $p$ \\
\hline Intercept & 1.75 & .30 & 240.52 & 5.76 & .00 \\
Age & -.00 & .01 & 254.83 & -.47 & .64 \\
Tenure & -.00 & .01 & 254.16 & -.12 & .91 \\
Industry & -.05 & .11 & 41.50 & -.43 & .67 \\
FSSB BL & .52 & .05 & 247.90 & 10.75 & .00 \\
Treatment & .01 & .11 & 41.21 & .05 & .96 \\
\hline
\end{tabular}

Note. The "Industry" variable indicates organizational affiliation ( $0=$ Industry A; $1=$ Industry B) BL = Baseline or time one; Treatment $=$ group assignment $(1=$ treatment; $0=$ control $)$. Level one $=$ individual employees.. 
Table 7

Multilevel model results from hypothesis two, the effect of supervisor learning adaptability by treatment on six month employee reported FSSB

\begin{tabular}{lrrrrr}
\hline \multicolumn{1}{c}{ Parameter } & $\beta$ & $S E$ & $d f$ & $t$ & $p$ \\
\hline Intercept & .54 & 1.07 & 53.31 & .51 & .62 \\
Age & .00 & .01 & 212.00 & .04 & .97 \\
Tenure & -.00 & .01 & 212.00 & -.16 & .87 \\
Industry & -.07 & .13 & 32.87 & -.51 & .61 \\
FSSB BL & .55 & .05 & 204.93 & 10.19 & .00 \\
Treatment & .50 & 1.15 & 40.37 & .43 & .67 \\
SUP LA 6M & .28 & .27 & 46.47 & 1.03 & .31 \\
Treatment*SUP & -.14 & .31 & 40.85 & -.44 & .66 \\
LA 6M & & & & &
\end{tabular}

Note. The "Industry" variable indicates organizational affiliation and acts as a control. BL = Baseline or time one; Treatment $=$ group assignment (treatment vs. control); SUP LA = Supervisor learning adaptability; $6 \mathrm{M}=$ six month or time 2 . Level one = individual employees; Level two (nesting variable) = work group.

Table 8

Multilevel model results from hypothesis three, the effect of the training on six month employee job satisfaction

\begin{tabular}{lrrrrr}
\hline \multicolumn{1}{c}{ Parameter } & $\beta$ & $S E$ & $d f$ & $t$ & $p$ \\
\hline Intercept & 1.07 & .23 & 255.00 & 4.70 & .00 \\
Age & .00 & .00 & 255.00 & 1.14 & .26 \\
Tenure & -.01 & .00 & 255.00 & -1.60 & .11 \\
Industry & .02 & .06 & 255.00 & .36 & .72 \\
Job Sat BL & .71 & .04 & 255.00 & 17.94 & .00 \\
Treatment & -.03 & .06 & 255.00 & -.50 & .62 \\
\hline
\end{tabular}

Note. The "Industry" variable indicates organizational affiliation and acts as a control. $\mathrm{BL}=$ Baseline or time one; Treatment $=$ group assignment (treatment vs. control). Level one $=$ individual employees; Level two (nesting variable) $=$ work group. 
Table 9

Multilevel model results from hypothesis four, the effect of supervisor learning adaptability by treatment on six month employee job satisfaction

\begin{tabular}{lrrrrr}
\hline \multicolumn{1}{c}{ Parameter } & $\beta$ & $S E$ & $d f$ & $t$ & $p$ \\
\hline Intercept & .24 & .58 & 212.00 & .41 & .68 \\
Age & .00 & .00 & 212.00 & .94 & .35 \\
Tenure & .00 & .00 & 212.00 & -.88 & .38 \\
Industry & .00 & .07 & 212.00 & -.06 & .95 \\
Job Sat BL & .69 & .04 & 212.00 & 16.42 & .00 \\
Treatment & .80 & .62 & 212.00 & 1.29 & .20 \\
SUP LA 6M & .23 & .15 & 212.00 & 1.58 & .12 \\
Treatment*SUP & -.22 & .17 & 212.00 & -1.33 & .19 \\
LA 6M & & & & & \\
\hline
\end{tabular}

Note. The "Industry" variable indicates organizational affiliation and acts as a control. BL $=$ Baseline or time one; Treatment $=$ group assignment (treatment vs. control); SUP LA $=$ Supervisor learning adaptability; $6 \mathrm{M}=$ six month or time 2 . Level one = individual employees; Level two (nesting variable) $=$ work group.

Table 10

Means and standard deviations for employee and supervisor samples on primary study variables

\begin{tabular}{lrr}
\hline Study Variable & $M$ & $S D$ \\
\hline Employee-Reported FSSB BL & 3.02 & 1.12 \\
Employee Job Satisfaction BL & 3.85 & .83 \\
Employee-Reported FSSB 6M & 3.24 & 1.07 \\
Employee Job Satisfaction 6M & 3.94 & .71 \\
Employee LA 6M & 3.84 & .48 \\
Employee LA 12M & 3.80 & .60 \\
& & \\
Supervisor-Reported FSSB BL & 2.84 & .82 \\
Supervisor Job Satisfaction BL & 3.98 & .75 \\
Supervisor-Reported FSSB 6M & 3.45 & .50 \\
Supervisor Job Satisfaction 6M & 4.02 & .46 \\
Supervisor LA 6M & 3.75 & .39 \\
Supervisor LA 12M & 3.79 & .34 \\
\hline Note. Employee ( $n=291)$ statistics provided at the top half of the table, \\
and supervisor $(n=23)$ statistics provided on the bottom half of the \\
table. LA = learning adaptability; BL = baseline or time 1; 6M = six \\
month follow-up or time 2; 12M = twelve month follow-up or time 3.
\end{tabular}




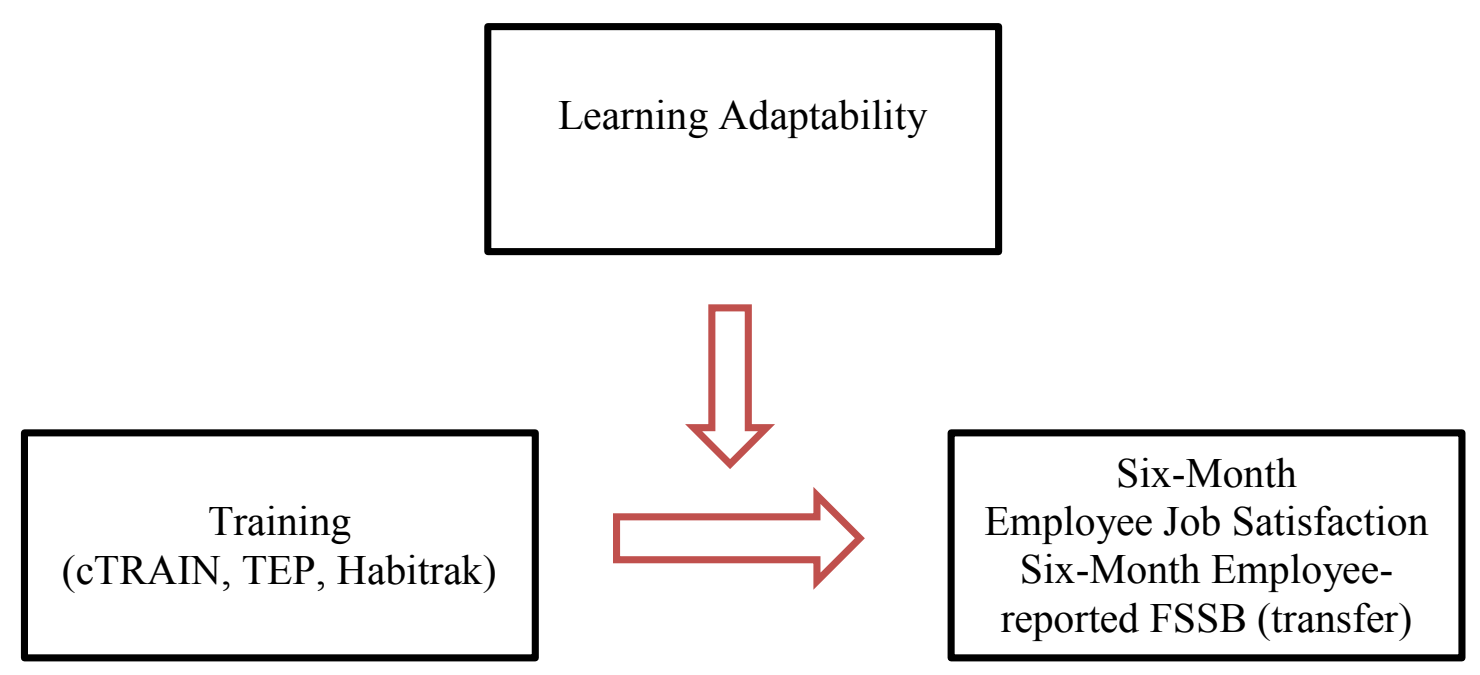

Figure 1. Theoretical model of hypotheses and predicted relationships 


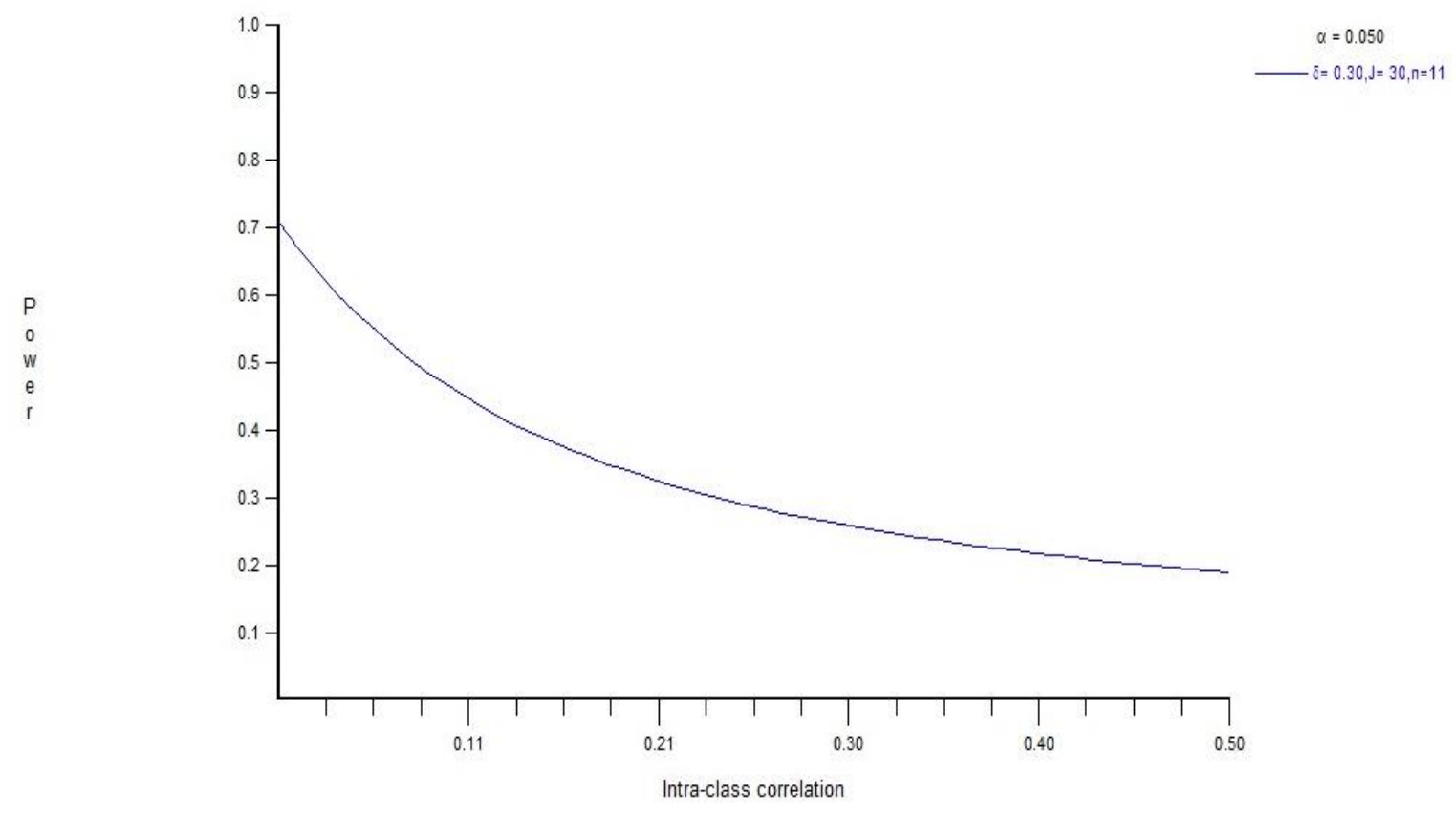

Figure 2. Estimate of statistical power for treatment and control groups 


\section{References}

Allen, T. D., Herst, D. E. L., Bruck, C. S., \& Sutton, M. (2000). Consequences associated with work-to-family conflict: A review and agenda for future research. Journal of Occupational Health Psychology, 5(2), 278-308.

Alliger, G. M., Tannenbaum, S. I., Bennett, W., Traver, H., \& Shotland, A. (1997). A meta-analysis of the relations among training criteria. Personnel psychology, $50(2), 341-358$.

Allworth, E., \& Hesketh, B. (1999, June). Construct-oriented biodata: Capturing changerelated and contextually relevant future performance. International Journal of Selection and Assessment, 7(2), 97-111.

Anger, W. K., Rohlman, D. S., Kirkpatrick, J., Reed, R. R., Lundeen, C. A., \& Eckerman, D. A. (2001). cTRAIN: a computer-aided training system developed in SuperCard for teaching skills using behavioral education principles. Behavior Research Methods, Instruments, \& Computers, 33(2), 277-281.

Baldwin, T. T., \& Ford, J. K. (1988). Transfer of training: A review and directions for future research. Personnel psychology, 41(1), 63-105.

Baron, R. M., \& Kenny, D. A. (1986). The moderator-mediator variable distinction in social psychological research: Conceptual, strategic, and statistical considerations. Journal of personality and social psychology, 51(6), 1173.

Barrick, M. R., \& Mount, M. K. (1991). The big five personality dimensions and job performance: a meta-analysis. Personnel psychology, 44(1), 1-26. 
Bell, B. S., \& Kozlowski, S. W. (2008). Active learning: effects of core training design elements on self-regulatory processes, learning, and adaptability. Journal of Applied Psychology, 93(2), 296.

Berkman, L. F., Buxton, O., Ertel, K., \& Okechukwu, C. (2010). Managers’ practices related to work-family balance predict employee cardiovascular risk and sleep duration in extended care settings. Journal of occupational health psychology, $15(3), 316$.

Bindl, U., \& Parker, S. K. (2010). Proactive work behavior: Forward-thinking and change-oriented action in organizations (Vol. 2, pp. 567-598). American Psychological Association.

Blume, B. D., Ford, J. K., Baldwin, T. T., \& Huang, J. L. (2010). Transfer of training: A meta-analytic review. Journal of Management, 36(4), 1065-1105.

Burke, L. A., \& Hutchins, H. M. (2007). Training transfer: An integrative literature review. Human resource development review, 6(3), 263-296.

Button, S. B., Mathieu, J. E., \& Zajac, D. M. (1996). Goal orientation in organizational research: A conceptual and empirical foundation. Organizational behavior and human decision processes, 67(1), 26-48.

Carlson, D. S., Kacmar, K. M., \& Williams, L. J. (2000). Construction and initial validation of a multidimensional measure of work-family conflict. Journal of Vocational Behavior, 56, 249-276.

Cascio, W. F. (2003). Changes in workers, work, and organizations. Handbook of psychology. Retrieved from http://onlinelibrary.wiley.com/doi/10.1002/0471264385.wei1216/full 
Caspi, A., \& Roberts, B. W. (2001). Personality development across the life course: The argument for change and continuity. Psychological Inquiry, 12(2), 49-66.

Chen, G., Gully, S. M., Whiteman, J.-A., \& Kilcullen, R. N. (2000). Examination of relationships among trait-like individual differences, state-like individual differences, and learning performance. Journal of Applied Psychology, 85(6), 835.

Chen, G., Thomas, B., \& Wallace, J. C. (2005). A multilevel examination of the relationships among training outcomes, mediating regulatory processes, and adaptive performance. Journal of Applied Psychology, 90(5), 827.

Chiaburu, D. S., \& Lindsay, D. R. (2008). Can do or will do? The importance of selfefficacy and instrumentality for training transfer. Human Resource Development International, 11(2), 199-206.

Clark, H. B., Wood, R., Kuehnel, T., Flanagan, S., Mosk, M., \& Northrup, J. T. (1986). Preliminary validation and training of supervisory interactional skills. Journal of Organizational Behavior Management, 7(1-2), 95-116.

Colquitt, J. A., \& Simmering, M. J. (1998). Conscientiousness, goal orientation, and motivation to learn during the learning process: A longitudinal study. Journal of applied psychology, 83(4), 654.

Colquitt, J. A., LePine, J. A., \& Noe, R. A. (2000). Toward an integrative theory of training motivation: a meta-analytic path analysis of 20 years of research. Journal of applied psychology, 85(5), 678.

Crant, J. M. (2000). Proactive behavior in organizations. Journal of management, 26(3), $435-462$. 
Dean, M. A., Conte, J. M., \& Blankenhorn, T. R. (2006). Examination of the predictive validity of Big Five personality dimensions across training performance criteria. Personality and Individual Differences, 41(7), 1229-1239.

Demerouti, E., Bakker, A. B., Nachreiner, F., \& Schaufeli, W. B. (2001). The job demands-resources model of burnout. Journal of Applied psychology, 86(3), 499.

Devine, D. J., \& Kozlowski, S. W. (1995). Domain-specific knowledge and task characteristics in decision making. Organizational Behavior and Human Decision Processes, 64(3), 294-306.

Dudley, N. M., Orvis, K. A., Lebiecki, J. E., \& Cortina, J. M. (2006). A meta-analytic investigation of conscientiousness in the prediction of job performance: examining the intercorrelations and the incremental validity of narrow traits. Journal of Applied Psychology, 91(1), 40.

Eby, L. T., Casper, W. J., Lockwood, A., Bordeaux, C., \& Brinley, A. (2005). Work and family research in IO/OB: Content analysis and review of the literature (19802002). Journal of Vocational Behavior, 66(1), 124-197.

Ernst Kossek, E., \& Ozeki, C. (1998). Work-family conflict, policies, and the job-life satisfaction relationship: A review and directions for organizational behaviorhuman resources research. Journal of applied psychology, 83(2), 139.

Frone, M. R., Russell, M., \& Cooper, M. L. (1992). Antecedents and outcomes of workfamily conflict: Testing a model of the work-family interface. Journal of Applied Psychology, 77, 65-78. 
Fuller Jr., B., \& Marler, L. E. (2009). Change driven by nature: A meta-analytic review of the proactive personality literature. Journal of Vocational Behavior, 75(3), $329-345$.

Gajendran, R. S., \& Harrison, D. A. (2007). The good, the bad, and the unknown about telecommuting: meta-analysis of psychological mediators and individual consequences. Journal of Applied Psychology, 92(6), 1524.

Gilpin-Jackson, Y., \& Bushe, G. R. (2007). Leadership development training transfer: a case study of post-training determinants. Journal of Management Development, 26(10), 980-1004.

Grandey, A. A., \& Cropanzano, R. (1999). The conservation of resources model applied to work-family conflict and strain. Journal of Vocational Behavior, 54(2), 350370.

Greenhaus, J. H., \& Beutell, N. J. (1985). Sources of conflict between work and family roles. Academy of management review, 10(1), 76-88.

Griffin, B., \& Hesketh, B. (2004). Why openness to experience is not a good predictor of job performance. International Journal of Selection and Assessment, 12(3), 243251.

Hackman, J. R., \& Oldham, G. R. (1975). Work redesign. Reading, MA: AddisonWestley.

Hammer, L. B., \& Zimmerman, K. L. (2011). Quality of work life. Retrieved from http://psycnet.apa.org/books/12171/011 
Hammer, L. B., Ernst Kossek, E., Bodner, T., \& Crain, T. (2013). Measurement development and validation of the family supportive supervisor behavior shortform (FSSB-SF). Journal of Occupational Health Psychology, 18(3), 285-296.

Hammer, L. B., Kossek, E. E., Anger, W. K., Bodner, T., \& Zimmerman, K. L. (2011). Clarifying work-family intervention processes: The roles of work-family conflict and family-supportive supervisor behaviors. Journal of Applied Psychology, 96(1), 134.

Hammer, L. B., Kossek, E. E., Yragui, N. L., Bodner, T. E., \& Hanson, G. C. (2009). Development and validation of a multidimensional measure of family supportive supervisor behaviors (FSSB). Journal of Management, 35(4), 837-856.

Hamtiaux, A., Houssemand, C., \& Vrignaud, P. (2013). Individual and career adaptability: Comparing models and measures. Journal of Vocational Behavior, 83(2), 130-141.

Häusser, J. A., Mojzisch, A., Niesel, M., \& Schulz-Hardt, S. (2010). Ten years on: A review of recent research on the Job Demand-Control (-Support) model and psychological well-being. Work \& Stress, 24(1), 1-35.

Herold, D. M., Davis, W., Fedor, D. B., \& Parsons, C. K. (2002). Dispositional influences on transfer of learning in multistage training programs. Personnel Psychology, 55(4), 851-869.

Hesketh, B., \& Neal, A. (1999). Technology and performance. Pulakos (Eds.), The changing nature of performance: Implications for staffing, motivation, and development, 21-55. 
Hobfoll, S. E. (1989). Conservation of resources: A new attempt at conceptualizing stress. American psychologist, 44(3), 513.

Hobfoll, S. E., \& Shirom, A. (2001). Conservation of resources theory: Applications to stress and management in the workplace. Retrieved from http://psycnet.apa.org/psycinfo/2001-14053-003

Holton, E. F., III. (1996). The flawed four-level evaluation model. Human Resource Development Quarterly, 7, 5-21.

Hulin, C.L. \& Glomb, T.M. (1999). Contingent employees: Individual and organizational considerations. In D. R. Ilgen \& E. D. Pulakos (Eds.), The changing nature of performance: Implications for staffing, motivation, and development (pp. 87-118). San Francisco: Jossey-Bass.

Kahn, R.L., Wolfe, D.M., Quinn, R., Snoek, J.D., \& Rosenthal, R.A. (1964). Organizational Stress. New York: Wiley.

Karasek Jr, R. A. (1979). Job demands, job decision latitude, and mental strain: Implications for job redesign. Administrative science quarterly, 285-308.

Karasek, R. A., \& Theorell, T. (1990). Healthy work. New York: Basic Books.

Katz, D., \& Kahn, R.L. (1978). The social psychology of organizations (2nd ed.) New York: Wiley.

Kirkpatrick, D. L. (1998). Evaluating training programs: The four levels. San Francisco, CA: Berrett-Koehler. (Original work published 1959)

Kossek, E. E., Pichler, S., Bodner, T., \& Hammer, L. B. (2011). Workplace social support and work-family conflict: A meta-analysis clarifying the influence of 
general and work-family-specific supervisor and organizational support. Personnel Psychology, 64(2), 289-313.

Kozlowski, S. W. (1998). Training and developing adaptive teams: Theory, principles, and research. Retrieved from http://psycnet.apa.org/index.cfm?fa=main.doiLanding\&uid=1998-06532-005

Kozlowski, S. W., Gully, S. M., Brown, K. G., Salas, E., Smith, E. M., \& Nason, E. R. (2001). Effects of training goals and goal orientation traits on multidimensional training outcomes and performance adaptability. Organizational behavior and human decision processes, 85(1), 1-31.

Kozlowski, S. W., Toney, R. J., Mullins, M. E., Weissbein, D. A., Brown, K. G., \& Bell, B. S. (2001). Developing adaptability: A theory for the design of integratedembedded training systems. Advances in human performance and cognitive engineering research, 1, 59-123.

Kraiger, K., Ford, J. K., \& Salas, E. (1993). Application of cognitive, skill-based, and affective theories of learning outcomes to new methods of training evaluation. Journal of applied psychology, 78(2), 311.

Lapierre, L. M., \& Allen, T. D. (2006). Work-supportive family, family-supportive supervision, use of organizational benefits, and problem-focused coping: Implications for work-family conflict and employee well-being. Journal of Occupational Health Psychology, 11, 169-181.

Lee, S., \& Klein, H. J. (2002). Relationships between conscientiousness, self-efficacy, self-deception, and learning over time. Journal of Applied Psychology, 87(6), 1175. 
Lee, D., \& Sabatino, K. (1998). Evaluating guided reflection: A U.S. case study. International Journal of Training and Development, 2, 162-170.

Lee, R., \& Wilbur, E. R. (1985). Age, education, job tenure, salary, job characteristics, and job satisfaction: A multivariate analysis. Human Relations, 38(8), 781-791.

LePine, J. A., Colquitt, J. A., \& Erez, A. (2000). Adaptability to changing task contexts: Effects of general cognitive ability, conscientiousness, and openness to experience. Personnel Psychology, 53(3), 563-593.

Lim, D. H., \& Morris, M. L. (2006). Influence of trainee characteristics, instructional satisfaction, and organizational climate on perceived learning and training transfer. Human Resource Development Quarterly, 17(1), 85-115.

Lord, R.G. \& Smith, W.G. (1999). Leadership and the changing nature of performance. In D. R. Ilgen \& E. D. Pulakos (Eds.), The changing nature of performance: Implications for staffing, motivation, and development (pp. 192-239). San Francisco: Jossey-Bass.

Major, D. A., Turner, J. E., \& Fletcher, T. D. (2006). Linking proactive personality and the Big Five to motivation to learn and development activity. Journal of Applied Psychology, 91(4), 927.

Martocchio, J. J., \& Judge, T. A. (1997). Relationship between conscientiousness and learning in employee training: Mediating influences of self-deception and selfefficacy. Journal of Applied Psychology, 82(5), 764-773.

Maurer, T. J. (2001). Career-relevant learning and development, worker age, and beliefs about self-efficacy for development. Journal of management, 27(2), 123-140. 
McCrae, R. R., \& Costa Jr, P. T. (1997). Conceptions and correlates of openness to experience. Retrieved from http://doi.apa.org/psycinfo/1997-08808-031

McCrae, R. R., \& Sutin, A. R. (2009). Openness to experience. Retrieved from http://psycnet.apa.org/psycinfo/2009-12071-017

Mesmer-Magnus, J. R., \& Viswesvaran, C. (2005). Convergence between measures of work-to-family and family-to-work conflict: A meta-analytic examination. Journal of Vocational Behavior, 67(2), 215-232.

Naquin, S. S., \& Holton, E. F. (2002). The effects of personality, affectivity, and work commitment on motivation to improve work through learning. Human Resource Development Quarterly, 13(4), 357-376.

Neal, M. B., \& Hammer, L. B. (2007). Working couples caring for children and aging parents: Effects on work and well-being. Lawrence Erlbaum Associates Publishers. Retrieved from http://psycnet.apa.org/psycinfo/2006-21532-000

Noe, R. A., \& Colquitt, J. A. (2002). Planning for training impact: Principles of training effectiveness. Creating, implementing, and managing effective training and development, 53-79.

Noe, R. A., \& Wilk, S. L. (1993). Investigation of the factors that influence employees' participation in development activities. Journal of Applied Psychology, 78, 291302.

Offermann, L. R., \& Gowing, M. K. (1990). Organizations of the future: Changes and challenges. American Psychologist, 45(2), 95. 
Olson, R., \& Winchester, J. (2008). Behavioral self-monitoring of safety and productivity in the workplace: A methodological primer and quantitative literature review. Journal of Organizational Behavior Management, 28(1), 9-75.

Parker, S. K., \& Sprigg, C. A. (1999). Minimizing strain and maximizing learning: the role of job demands, job control, and proactive personality. Journal of Applied Psychology, 84(6), 925.

Patel, L. (2010). ASTD State of the industry report 2010. Alexandria, VA: American Society for Training \& Development.

Phillips, P. P., \& Phillips, J. J. (2002). Eleven reasons why training and development fails... and what you can do about it. Training, 39(9), 78-85.

Ployhart, R. E., \& Bliese, P. D. (2006). Individual adaptability (I-ADAPT) theory: Conceptualizing the antecedents, consequences, and measurement of individual differences in adaptability. Advances in human performance and cognitive engineering research, 6, 3-39.

Probst, T. M. (2005). Economic stressors. In J. Barling, E. K. Kelloway, \& M. R. Frone, M. R. (Eds.), Handbook of work stress (267-297). Sage.

Probst, T. M. (2008). Job insecurity. Handbook of organizational behavior, 178-195.

Pulakos, E. D., Arad, S., Donovan, M. A., \& Plamondon, K. E. (2000). Adaptability in the workplace: Development of a taxonomy of adaptive performance. Journal of Applied Psychology, 85(4), 612-624.

Quick, J. C., \& Tetrick, L. E. (2003). Handbook of occupational health psychology. Washington, D.C.: American Psychological Assoc. 
Quiñones, M. A., Ford, J. K., Sego, D. J., \& Smith, E. M. (1995). The effects of individual and transfer environment characteristics on the opportunity to perform trained tasks. Training Research Journal, 1, 29-48.

Raudenbush, S. W., Spybrook, J., Congdon, R., Liu, X. F., \& Martinez, A. (2011). Optimal Design Software for Multilevel and Longitudinal Research (Version 3.01) [Software]. Available from www.wtgrantfoundation.org.

Richman-Hirsch, W. L. (2001). Posttraining interventions to enhance transfer: The moderating effects of work environments. Human Resources Development Quarterly, 12, 105-119.

Roberts, B. W., Walton, K. E., \& Viechtbauer, W. (2006). Patterns of mean-level change in personality traits across the life course: a meta-analysis of longitudinal studies. Psychological bulletin, 132(1), 1.

Rubin, D. (1996). Multiple imputation after 18+ years. Journal of the American Statistical Association, 91, 473-489.

Ruona, E. A. W., Leimbach, M., Holton III, F. E., \& Bates, R. (2002). The relationship between learner utility reactions and predicted learning transfer among trainees. International. Journal of Training and Development, 6(4), 218-228.

Salas, E., Tannenbaum, S. I., Kraiger, K., \& Smith-Jentsch, K. A. (2012). The science of training and development in organizations: What matters in practice. Psychological science in the public interest, 13(2), 74-101.

Seibert, S. E., Crant, J. M., \& Kraimer, M. L. (1999). Proactive personality and career success. Journal of Applied Psychology, 84, 416-427. 
Sitzmann, T., Brown, K. G., Casper, W. J., Ely, K., \& Zimmerman, R. D. (2008). A review and meta-analysis of the nomological network of trainee reactions. Journal of Applied Psychology, 93(2), 280.

Smith-Jentsch, K. A., Jentsch, F. G., Payne, S. C., \& Salas, E. (1996). Can pretraining experiences explain individual differences in learning? Journal of applied Psychology, 81(1), 110.

Smith, E. M., Ford, J. K., \& Kozlowski, S. W. (1997). Building adaptive expertise: Implications for training design strategies. Retrieved from http://psycnet.apa.org/index.cfm?fa=main.doiLanding\&uid=1997-97128-004

Stewart, G. L. (1999). Trait bandwidth and stages of job performance: Assessing differential effects for conscientiousness and its subtraits. Journal of Applied Psychology, 84(6), 959.

Stewart, G. L., Carson, K. P., \& Cardy, R. L. (1996). The joint effects of conscientiousness and self-leadership training on employee self-directed behavior in a service setting. Personnel Psychology, 49(1), 143-164.

Tabachnick, B. G., \& Fidell, L. S. (2013). Using Multivariate Statistics (6th ed.). Boston, MA: Pearson.

Thomas, L. T., \& Ganster, D. C. (1995). Impact of family-supportive work variables on work-family conflict and strain: a control perspective. Journal of applied psychology, 80(1), 6 .

Thoresen, C. J., Bradley, J. C., Bliese, P. D., \& Thoresen, J. D. (2004). The big five personality traits and individual job performance growth trajectories in 
maintenance and transitional job stages. Journal of Applied Psychology, 89(5), 835.

Velada, R., Caetano, A., Michel, J. W., Lyons, B. D., \& Kavanagh, M. J. (2007). The effects of training design, individual characteristics and work environment on transfer of training. International Journal of Training and Development, 11(4), $282-294$.

Verhoeven, C., Maes, S., Kraaij, V., \& Joekes, K. (2003). The job demand-control-social support model and wellness/health outcomes: A European study. Psychology and Health, 18(4), 421-440.

Viswesvaran, C., Sanchez, J. I., \& Fisher, J. (1999). The role of social support in the process of work stress: A meta-analysis. Journal of Vocational Behavior, 54(2), $314-334$.

Vroom, V. H. (1964). Work and motivation. New York: Wiley.

Wallace, J., \& Chen, G. (2005). Development and validation of a work-specific measure of cognitive failure: Implications for occupational safety. Journal of Occupational and Organizational Psychology, 78, 615-632.

Wang, M. O., Zhan, Y., McCune, E., \& Truxillo, D. (2011). Understanding newcomers' adaptability and work-related outcomes: Testing the mediating roles of perceived P-E fit variables. Personnel Psychology, 64(1), 163-189. 
Appendix

\title{
Additional Study Details and Materials
}

\author{
Brief Discussion Regarding my Personal Role in Data Collection
}

I began my graduate training in industrial-organizational psychology at Portland State University in the summer of 2012. At this time, research collaborators had already conducted pilot surveys, measuring several organizational outcomes and health data (both psychological, physical, objective, and subjective) for the SHIP intervention study. Upon my arrival, I was immediately involved in administering, collecting, and entering baseline survey data. This involved personally going to both organizations, passing out paper surveys, answering surveyrelated questions from participants, being trained in, and collecting blood pressure data, as well as measuring height, weight, fat percentage, BMI, and other objective measures of physical health. These data were collected in multiple sessions, two-three times per week on average, over the course of several weeks. I personally entered all objective health data into SPSS at baseline. I later trained research assistants to do this task at six months and twelve months. I was also trained in Teleform, a software package designed to automatically translate hand-written survey data into an SPSS spreadsheet. I wrote the protocol for Teleform data entry, and trained other researchers to use this software to enter survey data at six and twelve months.

Directly following completion of baseline data collection, I was involved in administering the supervisor, computer-based training, cTRAIN (Anger et al., 2001). This involved explaining the purpose of the training to groups (group sizes ranged from 2-8) of supervisors, setting up the software and computers so that they were ready for supervisors to begin the training, and then transferring training related data from individual computers to a central electronic location. During and following the training, I would answer any questions that supervisors had regarding training. This often involved clarifying the importance of familysupportive supervision, or reiterating practical tips for how to initiate FSSB with their employees. Directly following the training, I would personally sit with an individual supervisor, help him/her to select realistic goals, teach him/her to use the behavior tracking application, habiTRAK (Olson $\&$ Winchester, 2008). After fourteen days, research collaborators collected the iPods back from supervisors. I personally retrieved data from the goal tracking application, and entered these data into an excel spreadsheet, analyzed the data, created individual- and group-level reports. A meeting was scheduled with all supervisors who had participated in the training, and I shared aggregated results from the goal tracking exercise with the group of supervisors (and gave individual reports privately to each supervisor), prompted and recorded qualitative feedback during these sessions, answered questions, and re-iterated the importance of the behaviors learned during training.

My involvement in data collection at baseline, my involvement with supervisor training, and my interaction with participants prompted the question: are some supervisors more dispositionally prepared to learn and adopt lessons from the training? This question led to an investigative search for a measure that might best answer this question, and potentially be introduced during six and twelve month follow-up. The I-ADAPT-M was such a measure, and was added to the survey at six, and twelve months. My involvement in data collection for six and twelve months continued, and I was also tasked with data management. This involved cleaning the overall dataset, merging data across waves, and writing syntax for overall intervention analyses. 


\section{Consent Form}

You are invited to participate in a study conducted by Drs. Leslie Hammer, Donald Truxillo, and Todd Bodner at Portland State University. They are studying the factors affecting employees' safety, health, and work experiences. All workers at the Water Bureau and Bureau of Transportation in construction-related fields are invited to participate in the study.

If you decide to participate, we ask that you complete two questionnaires, which should each take about 20 minutes of your time. The surveys contain questions about your thoughts, feelings, and behaviors related to your job.

Physical testing will occur at this time, as well as in 6 months, and in 12 months from now. You will be asked to submit the following health measurements: blood pressure, and a measurement body composition including height and weight. Any problems you have with the health assessment testing will be discussed during this time period, or at any other time you have questions.

The surveys and physical testing will take place at your place of work and during your scheduled work hours.

\section{Frequently Asked Questions}

\section{How will my privacy be protected?}

We will protect your privacy in the following ways:

1. Your name or other protected information will not be used in any published documents.

2. Only research personnel associated with the study will be able to access your information and these individuals will keep your information confidential.

3. The code key, linking your name to your participant code and study data will be stored in a locked and password-protected computer file, with access limited only to investigators and data managers.

\section{What are the risks and discomforts?}

There may be personal discomfort when answering questions about personal health behaviors.

You may refuse to answer any of the questions. As a result of the measurement of blood pressure, we may find you have a health condition that needs treatment. You would be responsible for the costs of follow-up care and any missed workdays. The Principal Investigator can help you find follow-up care if you request his help. 
What are the benefits?

You may or may not personally benefit from being in this study. However, by serving as a subject, you may help us learn how to benefit others in the future.

\section{What are my alternatives?}

You may choose not to be in this study. You can choose not to answer survey items or have measurements made.

\section{Confidentiality and privacy of your protected health information:}

We will not use your name or your identity for publication or publicity purposes.

If you sign this form, you are agreeing that PSU may use and publish the health information collected and created in this research study.

You have the right to revoke this authorization and can withdraw your permission for us to use your information for this research by sending a written request to the Investigator listed at the bottom of the research consent form. If you do send a letter to the Principal Investigator, the use and disclosure of your protected health information will stop as of the date she receives your request. However, the Principal Investigator is allowed to use and disclose information collected before the date of the letter or collected in good faith before your letter arrives.

The information about you that is used or disclosed in this study may be re-disclosed and no longer protected under federal law.

Costs: There will be no direct cost to you for participating in the study. Liability:

If you have concerns or questions about your participation in this study or your rights as a research subject, please contact the Human Subjects Research Review Committee, Research + Strategic Partnerships (RSP), PO Box 751, Portland, OR 97207, (503) 7254288 / 1-877- 480-4400. If you have questions about the study itself, please contact Leslie Hammer at (503) 725-3971, hammerl@pdx.edu.

\section{Participation:}

You do not have to join this or any research study. If you do join, and later change your mind, you may quit at any time. If you refuse to join or withdraw early from the study, there will be no penalty or loss of any benefits to which you are otherwise entitled.

Your consent to participate in this study and your authorization to let us use and disclose your protected health information are voluntary. You may refuse to sign this consent and authorization form.

You will be given a copy of this consent form for your records. 
Your responses are completely confidential and will not be linked to you in any way. We do not ask you to provide your name or other identifying information on the survey. We ask you to provide the name of your workgroup only so that we can analyze the data by workgroups. The results of this research will only be reported in aggregate form (everyone's information will be pooled together and summarized). No information on any individual or workgroup will be provided to management.

\section{Signatures:}

Your signature below indicates that you have read this entire form and that you agree to be in this study.

(Participant's name) ____(Participant's signature) (Date)

(Name of person obtaining consent) ___ __ (Signature of person obtaining consent) (Date) 


\section{Informed Consent: Computer-Based Training and Supportive Behavior Tracking}

You are participating in the SHIP (Safety \& Health Improvement Program) that is being implemented in your workgroup. As part of SHIP, you are being asked to complete a computer-based training session, as well as an exercise where you will track the number of performance and family-supportive behaviors you engage in over a two-week period. These activities will take you 30 minutes or longer. Today we are asking for your permission to use the data we collect related to these activities, (e.g. quiz scores and number and types of behaviors) to help us in evaluating the effectiveness of the SHIP program and to better understand how changes in the workplace may affect employees and managers. We will combine the information collected from SHIP with administrative data such as absenteeism rates. These data will be kept completely confidential. Only trained members of our research team will have access to this information. You were selected to complete this training and participate in this data collection because you are currently a supervisor or crew leader at your organization and your workgroup is participating in the SHIP leadership initiative.

While you are required to take part in the training as part of the SHIP roll-out, permission to use your data to help evaluate the training is voluntary and choosing not to collect these data will have no effect on your employment.

There are no anticipated risks to you for participating in the study. At no point will we share your individual results with anyone at your organization or outside the research project. The study results that will be shared with your company will describe findings from the participants as a group so your individual responses cannot be identified. Your confidentiality will be protected to the maximum extent allowable by law. You may discontinue participation in the data collection at any time.

If you have any questions, you may contact Dr. Leslie Hammer (503-725-3971) at Portland State University. Please keep this letter for your records.

If you have any questions or concerns about your role and rights as a research participant, would like to obtain information or offer input, or register a complaint about this study, you may contact anonymously if you wish, a member of the Human Subjects Research Review Committee, Office of Research and Sponsored Projects, Unitus Building $6^{\text {th }}$ Floor, Portland State University, Portland, OR 97202, 503-725-4288, or 1-877-480-4400. Sincerely,

Dr. Leslie Hammer

Department of Psychology

Portland State University 
By signing this consent form, you indicate that you allow the researchers to use your data to help evaluate the training activities.

Participant Signature

\section{Date}

Researcher Signature

Date 